\title{
¿Energetics of Transient Eddies Related to the Midwinter Minimum of the North Pacific Storm-Track Activity
}

\author{
SATORU OKAJIMA, ${ }^{\mathrm{a}}$ HISASHI NAKAMURA, ${ }^{\mathrm{a}}$ and YOHAI KASPI ${ }^{\mathrm{b}}$ \\ ${ }^{a}$ Research Center for Advanced Science and Technology, The University of Tokyo, Tokyo, Japan \\ ${ }^{\mathrm{b}}$ Department of Earth and Planetary Sciences, Weizmann Institute of Science, Rehovot, Israel
}

(Manuscript received 9 February 2021, in final form 7 November 2021)

\begin{abstract}
Storm-track activity over the North Pacific (NP) climatologically exhibits a clear minimum in midwinter, when the westerly jet speed sharply maximizes. This counterintuitive phenomenon, referred to as the "midwinter minimum (MWM)," has been investigated from various perspectives, but the mechanisms are still to be unrevealed. Toward better understanding of this phenomenon, the present study delineates the detailed seasonal evolution of climatological-mean Eulerian statistics and energetics of migratory eddies along the NP storm track over 60 years. As a comprehensive investigation of the mechanisms for the MWM, this study has revealed that the net eddy conversion/generation rate normalized by the eddy total energy, which is independent of eddy amplitude, is indeed reduced in midwinter. The reduction from early winter occurs mainly due to the decreased effectiveness of the baroclinic energy conversion through seasonally weakened temperature fluctuations and the resultant poleward eddy heat flux. The reduced net normalized conversion/generation rate in midwinter is also found to arise in part from the seasonally enhanced kinetic energy conversion from eddies into the strongly diffluent Pacific jet around its exit. The seasonality of the net energy influx also contributes especially to the spring recovery of the net normalized conversion/generation rate. The midwinter reduction in the normalized rates of both the net energy conversion/generation and baroclinic energy conversion was more pronounced in the period before the late 1980s, during which the MWM of the storm-track activity was climatologically more prominent.
\end{abstract}

KEYWORDS: Atmospheric circulation; Storm tracks; Energy budget/balance

\section{Introduction}

Extratropical transient eddies largely regulate daily weather variations in midlatitudes, while interacting with the climatological-mean westerlies and low-frequency quasi-stationary circulation anomalies. These eddies play an important role in maintaining the time mean temperature field and hemispheric energy budget. Improved mechanistic understanding of these eddies is thus important for climate dynamics and regional weather forecasts. These transient eddies successively move eastward through a given midlatitude location, accounting locally for a major fraction of high-frequency fluctuations of a given atmospheric variable. Using a 10-yr atmospheric analysis data over the extratropical Northern Hemisphere, Blackmon (1976) decomposed the temporal variance of 500-hPa geopotential height locally into the contributions from high-pass-, bandpass-, and low-pass-filtered components, whose periods are less than 2 days, 2.5-6 days, and longer than 10 days, respectively. He suggested that maritime regions of large variance of the bandpass-filtered fluctuations closely correspond to those of frequent cyclone passage over the North Atlantic and Pacific basins, which were thus referred to as "storm tracks." Blackmon et al. (1977) indicated that those storm tracks are characterized by strong lower-tropospheric

DDenotes content that is immediately available upon publication as open access.

Corresponding author: Satoru Okajima, okajima@atmos.rcast. u-tokyo.ac.jp poleward eddy heat flux based on the bandpass-filtered fluctuations, which is now commonly used as a measure of baroclinic eddy activity. In fact, poleward heat transport associated with high-frequency (sub-weekly) eddies are pronounced along the major storm tracks over the North Pacific (NP), North Atlantic, and south Indian Ocean. They tend to coincide closely with lower-tropospheric eddy-driven westerly jets and regions of strong near-surface baroclinicity anchored along major oceanic frontal zones (Nakamura et al. 2004).

Many studies have investigated climatological-mean, interannual or longer-scale variability, and seasonal evolution of storm-track activity based on similar techniques based on Eulerian statistics (e.g., Chang et al. 2002). Taking advantage of the Eulerian statistics, Lee and Kim (2003) and Nakamura et al. (2004) clarified the maintenance mechanisms for the westerly jets and storm tracks by separating eddy-driven, subpolar jets from the thermally driven subtropical jets. As argued by Nakamura et al. (2004), this clear separation holds over the North Atlantic throughout the cold season, while it holds over the NP only in the shoulder seasons (i.e., autumn and spring). Over the midwinter NP, a stronger subtropical jet is merged with a subpolar jet to form a hybrid jet.

According to linear theory of baroclinic instability, the stronger the vertical shear of zonal flow (equivalent to meridional temperature gradient through thermal wind balance) is, the larger the growth rate for most unstable eddies $[\sigma=0.31(f / N)(d U / d z)$; Eady 1949] becomes. Consistently, the climatological-mean North Atlantic storm-track activity measured by RMS of sub-weekly fluctuations of upper-tropospheric geopotential height is strongest in midwinter, when the upper-tropospheric westerly jet speed tends to maximize. 
Conversely, the corresponding NP storm-track activity exhibits its minimum in midwinter and becomes weaker than its Atlantic counterpart (Nakamura 1992). This is obviously inconsistent with baroclinic instability theory, since the westerly jet speed over the NP clearly maximizes in midwinter and is greater than over the midwinter Atlantic.

This counterintuitive phenomenon, referred to as the "midwinter minimum (MWM)" or "midwinter suppression" of the NP storm-track activity, has long been investigated from various viewpoints. Nakamura (1992) and Nakamura et al. (2002) argued that an excessive propagation speed of baroclinic eddies inhibits their development of eddies by reducing their residence time within the baroclinic zone over the western Pacific. It was suggested that the excessively strong lateral shear of the extremely strong westerly jet in midwinter may also lead to suppressed growth rate of eddies (Harnik and Chang 2004; Deng and Mak 2005). This is based on the "barotropic governor" mechanism proposed by James (1987), who showed that enhanced lateral shear of a westerly jet acts to suppress baroclinic eddy growth. The importance of the excessive strength of the westerlies has been substantiated by Afargan and Kaspi (2017), who observed a clear suppression of high-frequency eddy activity also over the North Atlantic during years of a particularly strong westerly jet. A similar result was obtained for a southward-shifted jet regime over the North Atlantic by Madonna et al. (2019).

Nakamura and Sampe (2002) pointed out that upper-tropospheric eddies propagating into the midwinter NP tend to be trapped into the southward and upward shifted westerly jet core and thus separated from the surface baroclinic zone, which is unfavorable for effective baroclinic growth of eddies (Nakamura et al. 2004). Vertical structure of the westerly Pacific jet varies between the stronger and more subtropical "merged" regime (Lachmy and Harnik 2014, 2016) in midwinter and the weaker eddy-driven regime in autumn and spring, which may be responsible for the MWM (Yuval et al. 2018; Yuval and Kaspi 2018). Following on this, by tracking upper and lower level eddies in the storm track region, Hadas and Kaspi (2021) showed that the baroclinic coupling of storms diminishes when the jet is enhanced, leading to reduced baroclinic eddy growth.

Furthermore, the effect of diabatic heating associated with low-level clouds in the cold sector of a cyclone was argued by Chang (2001) and Chang and Song (2006). Through a Lagrangian tracking method, Penny et al. (2010) focused on the "seeding effect" of upper-level cyclonic eddies propagating from the Asian Continent upstream of the Pacific storm track. They argued that fewer cyclonic eddies propagating from the upstream is responsible for the MWM, while no such clear relationship was found in an independent analysis by Chang and Guo (2012). Penny et al. (2013) argued that the discrepancies are partly due to different perspectives concerning whether cold seasons are viewed individually or as a single large dataset. In addition, Park et al. (2010) and Lee et al. (2013) suggested the potential importance of the upstream orography on the MWM.

Despite these efforts, the governing mechanisms for the MWM of the NP storm-track activity have yet to be uncovered and are still under debate. The phenomenon becomes one of the most difficult issues remaining in extratropical atmospheric and climate dynamics. The MWM was successfully simulated in AGCM experiments (Christoph et al. 1997; Zhang and Held 1999), which has not led to full understanding of the detailed mechanisms though. Zhang and Held (1999) successfully simulated the MWM in a stochastic linear storm-track model, implying that it is mainly caused by linear dry dynamics. However, a similar effort by Whitaker and Sardeshmukh (1998) was unsuccessful. Using an atmospheric general circulation model (AGCM) with an idealized zonally symmetric setting, which reproduced the climatological conditions in the Pacific over the different seasons, Yuval et al. (2018) were able to reproduce the MWM demonstrating that zonal asymmetries are not essential for reproducing the MWM. Using a similar model with a seasonal dependent forcing, Novak et al. (2020) suggested the importance of the equatorward shift of the westerly jet in midwinter for the suppressed eddy activity.

Chang (2001) and Zhao and Liang (2019) examined the energetics of migratory eddies along the Pacific storm track as an attempt to understand dynamical processes underlying the MWM. Their arguments are, however, based largely on energy conversion/generation rates, which is, by definition, dependent on eddy amplitude and thus insufficient for fully explaining the mechanisms for the suppressed eddy activity. As a measure independent of eddy amplitude, Chang (2001) evaluated a local "growth rate" of a given process, defined as the related energy conversion divided by local eddy kinetic energy (EKE). Schemm and Rivière (2019) evaluated efficiency of the baroclinic conversion term, defined as the conversion normalized by the product of eddy amplitude and magnitude of background baroclinicity (Rivière and Joly 2006; Rivière et al. 2018). They suggested that the reduced efficiency of baroclinic conversion owing to an anomalous poleward tilt of eddies over the western NP poleward of $\sim 40^{\circ} \mathrm{N}$ contributes to MWM. Schemm et al. (2021) argued that more rapid development and decay of cyclones over the Kuroshio in midwinter is consistent with the reduction. Their evaluation is, however, conducted only for baroclinic conversion, and thus insufficient for full understanding of the mechanisms for MWM. Additionally, the NP storm track is zonally elongated rather than confined to the vicinity of the Kuroshio, and its MWM is therefore a basin-scale, nonlocal phenomenon. Therefore, a more comprehensive, three-dimensionally integrated energetics of eddies propagating along the NP storm track, which is independent of eddy amplitude, is required to clarify the mechanisms for the MWM, which is the main purpose of the present study.

This paper is organized as follows. Section 2 describes the data and analysis methods used in this study. Section 3 explores the climatological seasonal evolution of various Eulerian eddy statistics for the NP storm track. In section 4, the full energetics for the NP storm track are investigated, with particular focus on their seasonal evolution. Section 5 addresses long-term modulations of the MWM. Section 6 is for summary and discussion. 


\section{Data and analysis methods}

\section{a. Observational data}

In this study, 6-hourly atmospheric variables, including geopotential height, temperature, wind velocities, and diabatic heating rate in pressure coordinates as well as sea level pressure (SLP), are obtained from the Japanese 55-year reanalysis (JRA-55) by the Japan Meteorological Agency (JMA) (Kobayashi et al. 2015; Harada et al. 2016) for the period 1958-2017. The JRA-55 has been constructed with a fourdimensional variational data assimilation (4D-Var) system with TL319 horizontal resolution (equivalent to $55-\mathrm{km}$ resolution) and 60 vertical levels up to the $0.1-\mathrm{hPa}$ level. Those variables on a given pressure level are available on a $1.25^{\circ} \times 1.25^{\circ}$ grid. Diabatic heating rate has been decomposed into five terms: parameterized convective precipitation, large-scale gridscale precipitation, shortwave radiation, longwave radiation, and vertical diffusion. When diabatic heating associated only with precipitation is considered, we take the sum of the first two terms.

At each grid point, sub-weekly fluctuations of a given variable associated with synoptic-scale transient eddies have been extracted from the 6-hourly atmospheric reanalysis as its local deviations from their low-pass-filtered fields with an 8-day cutoff Lanczos filter. Local activity of those transient eddies is evaluated, for example, as the temporal variance based on sub-weekly fluctuations of meridional velocity or the covariance representing poleward eddy heat flux. A region of particularly large variance or covariance corresponds to a "storm track," along which transient eddies recurrently develop. Climatological-mean fields are calculated with a 31-day running mean.

\section{b. Energetics}

Eddy available potential energy (EAPE) and eddy kinetic energy (EKE) associated with sub-weekly synoptic-scale disturbances are defined as follows:

$$
\mathrm{EAPE}=\frac{R}{p S_{p}}\left[\frac{\left(T^{\prime 2}\right)_{C}}{2}\right], \mathrm{EKE}=\frac{\left(u^{\prime 2}+v^{2}\right)_{C}}{2}
$$

In (1), primes denote high-pass-filtered fields, subscripts " $C$ " the climatological-mean fields, and $S_{p}\left(\equiv-\overline{T_{c}} \partial \ln \overline{\theta_{c}} / \partial p\right)$ a stability parameter, where overbars denote horizontally averaged quantities over a specific domain. In (1), $u, v, T$ and $R$ represent zonal and meridional wind components, temperature, and the gas constant for dry air, respectively. In taking the horizontal average, grid points below the surface are masked out, based on the climatological-mean surface pressure. The same set of grid points are used for horizontal averaging for a particular level at which $S_{p}$ is calculated and the two adjacent levels, to minimize the effect of topography.

In the following equations, $\mathrm{CK}$ denotes the barotropic energy conversion (or KE conversion), CP the baroclinic energy conversion (or APE conversion), CQ the APE generation through diabatic processes, and ET the energy transfer from EAPE to EKE. Each of the energy conversion/generation terms is expressed as follows (cf. Tanaka et al. 2016):

$$
\begin{gathered}
\mathrm{CK}=\frac{\left(v^{2}-u^{\prime 2}\right)_{C}}{2}\left(\frac{d u_{c}}{d x}-\frac{d v_{c}}{d y}\right)-\left(u^{\prime} v^{\prime}\right)_{C}\left(\frac{d u_{c}}{d y}+\frac{d v_{c}}{d x}\right), \\
\mathrm{CP}=\frac{R}{p S_{p}}\left[-\left(u^{\prime} T^{\prime}\right)_{C} \frac{d T_{c}}{d x}-\left(v^{\prime} T^{\prime}\right)_{C} \frac{d T_{c}}{d y}\right] \\
\mathrm{CQ}=\frac{R}{p S_{p}}\left(Q^{\prime} T^{\prime}\right)_{C}, \\
\mathrm{ET}=-\frac{R}{p}\left(\omega^{\prime} T^{\prime}\right)_{C},
\end{gathered}
$$

where $Q$ denotes temperature tendency due to diabatic processes and $\omega$ is pressure velocity. In deriving (2), quasigeostrophic scaling is assumed and the tendency of horizontally averaged climatological-mean static stability is thus ignored.

In addition to those energy conversion terms from the climatological-mean background state, barotropic and baroclinic energy conversion rates from low-frequency variabilities, in which sub-weekly transient eddies are embedded, are also evaluated. In the following two equations, CKLF and CPLF denote the barotropic and baroclinic energy conversion rates from the low-frequency variability, respectively:

$$
\begin{aligned}
\mathrm{CKLF}= & {\left[\left(\frac{v^{\prime 2}-u^{\prime 2}}{2}\right)\left(\frac{\partial u_{L}}{\partial x}-\frac{\partial v_{L}}{\partial y}\right)-\left(u^{\prime} v^{\prime}\right)\left(\frac{\partial u_{L}}{\partial y}+\frac{\partial v_{L}}{\partial x}\right)\right] } \\
& -\left(u_{L} \frac{\partial \mathrm{EKE}}{\partial x}+v_{L} \frac{\partial \mathrm{EKE}}{\partial y}\right)-\left(u^{\prime} u_{L} \frac{\partial u_{L}}{\partial x}+u^{\prime} v_{L} \frac{\partial u_{L}}{\partial y}\right. \\
& \left.+v^{\prime} u_{L} \frac{\partial v_{L}}{\partial x}+v^{\prime} v_{L} \frac{\partial v_{L}}{\partial y}\right)
\end{aligned}
$$

$$
\begin{aligned}
\mathrm{CPLF}= & \frac{R}{p S_{p}}\left[-\left(u^{\prime} T^{\prime}\right) \frac{d T_{L}}{d x}-\left(v^{\prime} T^{\prime}\right) \frac{d T_{L}}{d y}\right] \\
& -\left(u_{L} \frac{\partial \mathrm{EAPE}}{\partial x}+v_{L} \frac{\partial \mathrm{EAPE}}{\partial y}\right) \\
& +\frac{R}{p S_{p}}\left(-T^{\prime} u_{L} \frac{\partial T_{L}}{\partial x}-T^{\prime} v_{L} \frac{\partial T_{L}}{\partial y}\right),
\end{aligned}
$$

where subscript " $L$ " represents low-pass-filtered anomalies as deviations from the climatological mean. CKLF and CPLF are calculated every $6 \mathrm{~h}$ based on (2e) and (2f), and their climatological-mean values indicate the climatological seasonal evolutions of energy conversions from the low-frequency variability. The derivation of these terms is described in appendix A. Note that, by this definition, "low-frequency variability" includes even interannual fluctuations, but the results are 
TABLE 1. List of the symbols for the normalized rates used in this study. All quantities are expressed in the unit of day ${ }^{-1}$.

\begin{tabular}{ll}
\hline \hline Symbol & \multicolumn{1}{c}{ Meaning } \\
\hline$\lambda_{\mathrm{CK}}$ & Rate of CK (barotropic energy conversion) normalized by (EKE + EAPE) \\
$\lambda_{\mathrm{CP}}$ & Rate of CP (baroclinic energy conversion) normalized by (EKE + EAPE) \\
$\lambda_{\mathrm{CQ}}$ & Rate of CQ (diabatic energy generation) normalized by (EKE + EAPE) \\
$\lambda_{\mathrm{EF}}$ & Rate of EF (net energy inflow/outflow) normalized by (EKE + EAPE) \\
$\lambda_{\mathrm{CKLF}}$ & Rate of CKLF (barotropic energy conversion from low-frequency variability) normalized by (EKE + EAPE) \\
$\lambda_{\mathrm{CPLF}}$ & Rate of CPLF (baroclinic energy conversion from low-frequency variability) normalized by (EKE + EAPE) \\
$\lambda_{\mathrm{Tot}}$ & Rate of total energy conversion/generation rate (sum of the above terms) normalized by (EKE + EAPE) \\
$\lambda_{\mathrm{EF}}$ & Rate of ET (energy transfer from EKE to EAPE) normalized by (EKE + EAPE) \\
\hline
\end{tabular}

qualitatively similar when low-frequency variability is defined as low-pass-filtered subseasonal deviations from the 31-day running mean fields.

The energy conversion/generation terms were integrated vertically from the surface to the $100-\mathrm{hPa}$ level and then integrated horizontally within a specified domain. This study focuses on the energetics of sub-weekly eddies along the NP storm track within the domain $\left(20^{\circ}-65^{\circ} \mathrm{N}, 130^{\circ} \mathrm{E}-130^{\circ} \mathrm{W}\right)$. When the energetics within a local domain is discussed, energy inflow or outflow by energy fluxes through its lateral boundaries (EF) needs to be estimated. The flux may be expressed as follows:

$$
\mathrm{EF}=\int_{p_{s}}^{p_{\mathrm{top}}}\left[\left(\Phi^{\prime} \mathbf{v}^{\prime}\right)_{C}+(\mathrm{EAPE}+\mathrm{EKE}) \mathbf{v}_{c}\right] d p
$$

where $\Phi$ is geopotential, $p_{s}$ denotes surface pressure, and $p_{\text {top }}$ is set to be $100 \mathrm{hPa}$.

For more quantitative discussion on the energetics based on (1), (2), and (3), the normalized rate ${ }^{1}$ of each of the conversion, generation and flux terms is evaluated by dividing it by the total energy of transient eddies defined as the sum of EAPE and EKE:

$$
\text { normalized rate } \equiv \frac{\langle\text { energy conversion } / \text { generation term }\rangle}{\langle\mathrm{EAPE}+\mathrm{EKE}\rangle} .
$$

Hereafter, we signify the normalized rate simply as " $\lambda$," and a subscript as listed in Table 1 is added in referring to a specific conversion/generation process. The unit of this

\footnotetext{
${ }^{1}$ The definition of the term is the same as that of efficiency used in some previous studies (e.g., Nakamura et al. 1987; Stephenson 1995; Kosaka and Nakamura 2010; Tanaka et al. 2016; Sung et al. 2019; Martineau et al. 2020). We nevertheless use the term normalized rate $(\lambda)$ in this study, to avoid any confusion with the definition of efficiency as the ratio of energy conversion/generation divided by the product of eddy energy and the magnitude of background baroclinicity (e.g., Schemm and Rivière 2019), which is analogous to thermal efficiency in thermodynamics. Additionally, the energy conversion/generation terms are normalized by eddy total energy (EKE + EAPE) in this study, rather than solely by EKE as in Chang (2001). Normalized by both EKE and EAPE is advantageous, because a particular conversion/generation term is directly related to either EKE or EAPE, which is effectively transferred into the other by the ET term. The results are essentially the same when normalized solely by EKE.
}

normalized energy conversion (or generation) rate is day ${ }^{-1}$, and its reciprocal thus gives a time scale of how long it would take to replenish the total eddy energy within the storm-track domain solely by a given conversion/generation process. Because the energy conversion/generation rates, by definition, depend on eddy amplitude, it is essential to evaluate the conversion/generation as its normalized rate, which is independent of eddy amplitude, for the eddy energetics for storm tracks. In the following, a negative value of $\lambda$ means that eddies are transferring energy to the mean flow or low-frequency variability.

\section{Climatology of the North Pacific storm-track activity}

We begin our analysis with exploring the seasonal evolution of the climatological activity of the NP storm track based on the atmospheric reanalysis that covers a longer period than in previous studies. Figure 1 shows the climatological-mean seasonal evolution of meridionally averaged eddy statistics around the axes of their local maxima at individual longitudes.

The variance of sub-weekly fluctuations in 300-hPa meridional wind $\left(V^{\prime} V_{300}^{\prime}\right)$ as a measure of the upper-level stormtrack activity exhibits its prominent MWM under the extremely strong westerly jet (Fig. 1a), while its counterpart for the $850-\mathrm{hPa}$ wind variance $\left(V^{\prime} V_{850}^{\prime}\right)$ is less clear and its early-winter peak is more distinct (Fig. 1b). The two peaks in $V^{\prime} V_{300}^{\prime}$ seem to accompany weak secondary maxima of the $300-\mathrm{hPa}$ westerly wind speed $\left(U_{300}\right)$ in the eastern NP (see 30 $\mathrm{m} \mathrm{s}^{-1}$ contour in Fig. 1a). The corresponding maxima of the 850 -hPa westerly intensity $\left(U_{850}\right)$ are more evident, as an indication of an eddy-driven jet. In early winter, the peak of $V^{\prime} V_{850}^{\prime}$ is stronger and extends farther eastward than in spring. To examine their seasonal evolutions more quantitatively, those Eulerian statistics are averaged within longitudinal sectors that correspond to the storm-track core regions. The MWM is distinct in $V^{\prime} V_{300}^{\prime}$ with a reduction by more than $20 \%$ from its spring peak (Fig. 1 d). By contrast, $V^{\prime} V_{850}^{\prime}$ peaks in early winter, then weakens slightly in midwinter and retains its intensity into spring (Fig. 1e). Such a distinct MWM in the storm-track activity as above is not observed over the North Atlantic for the period 1958/59-2016/17 (not shown), as pointed out by previous studies (e.g., Nakamura 1992).

Poleward eddy heat flux $\left(V^{\prime} T^{\prime}\right)$ is a measure of baroclinic development of eddies and related to the baroclinic energy conversion ( $\mathrm{CP}$ in section 2). We focus on the lower 
(a) V'V'300 RMS

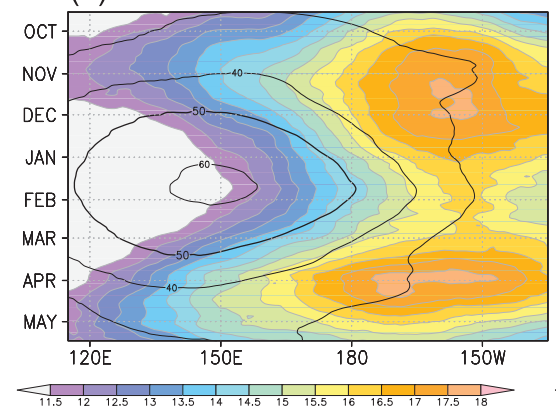

(d) V'V'300 180-150W

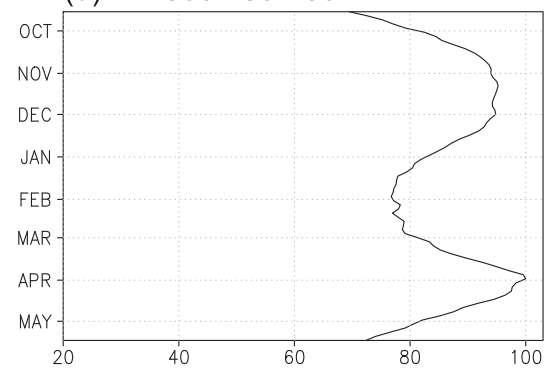

(b) V'V'850 RMS

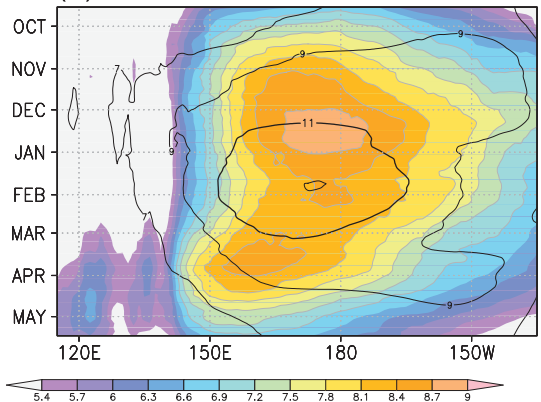

(e) V'V'850 160E-170W (c) V'T'850

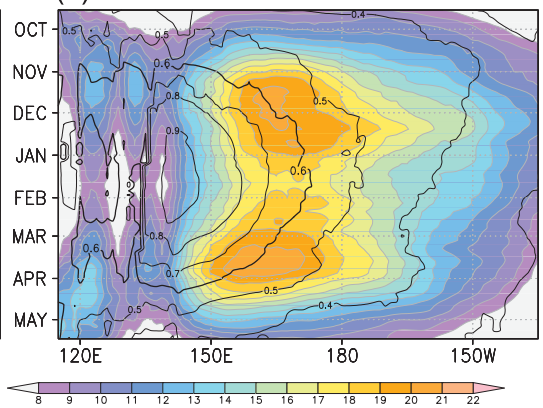

(f) V'T'850 150-180E
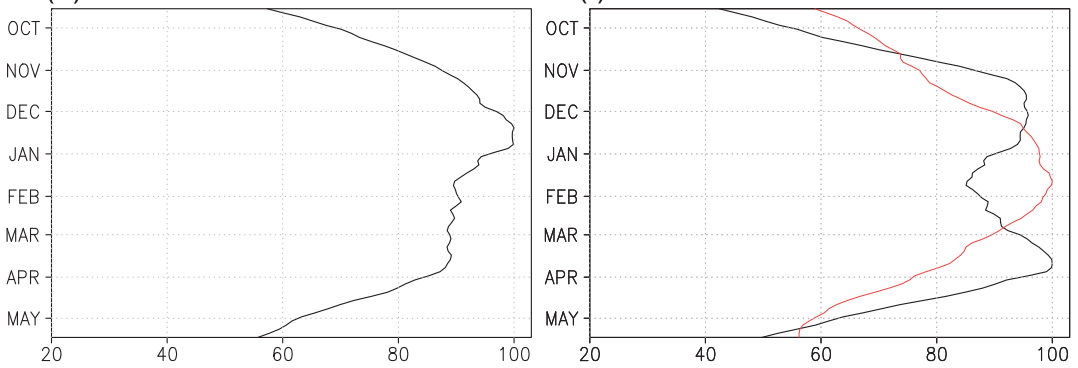

FIG. 1. Climatological seasonality in storm-track activity measured as RMS of sub-weekly fluctuations in meridional wind velocity ( $\mathrm{m} \mathrm{s}^{-1}$ ) at the (a) 300-hPa level $\left(V^{\prime} V_{300}^{\prime}\right)$ and (b) 850-hPa level $\left(V^{\prime} V_{850}^{\prime}\right)$. These statistics are meridionally averaged for 9 grids whose center is at the maximum of a given quantity in $20^{\circ}-60^{\circ} \mathrm{N}$ at each longitude. Contours denote the climatological westerly wind speed $\left(\mathrm{m} \mathrm{s}^{-1}\right)$ at the respective levels. (c) As in (b), but for 850-hPa poleward heat flux by sub-weekly transients $\left(V^{\prime} T_{850}^{\prime}\right)$. Contours represent 850 -hPa Eady growth rate $\left(\right.$ day $\left.{ }^{-1}\right)$ of the background state averaged meridionally around the $V^{\prime} T_{850}^{\prime}$ maxima at individual longitudes. Climatological seasonality in (d) averaged over $180^{\circ}-150^{\circ} \mathrm{W}$, (e) $V^{\prime} V_{850}^{\prime}$ over $160^{\circ} \mathrm{E}-170^{\circ} \mathrm{W}$, and (f) $V^{\prime} T_{850}^{\prime}$ (black) and the Eady growth rate (red) averaged over $150^{\circ} \mathrm{E}-180^{\circ}$ based on (a)-(c), respectively, as function of latitude. The values are indicated as the fractions (\%) of their climatological maxima.

troposphere, where $V^{\prime} T^{\prime}$ is prominent throughout the cold season. At the $850-\mathrm{hPa}, V^{\prime} T_{850}^{\prime}$ is largest around $40^{\circ} \mathrm{N}$ in the western NP, where a prominent oceanic frontal zone is located. Unlike $V^{\prime} V_{850}^{\prime}, V^{\prime} T_{850}^{\prime}$ shows a distinct MWM (Fig. 1c). In contrast, the climatological-mean 850-hPa Eady growth rate [EGR; $\sigma=0.31(f / N)(d U / d z)]$ exhibits a distinct midwinter maximum in the western NP (black contours in Fig. 1c), in agreement with Nakamura (1992). A close examination reveals, however, that the climatological-mean EGR is enhanced (suppressed) to the south (north) of the storm-track axis in midwinter (Yuval et al. 2018), which corresponds to the modulated vertical structure of the Pacific jet. Nevertheless, the net enhancement of EGR in midwinter maximizes around the axis. In theory, the growth rate of baroclinic eddies is therefore supposed to maximize in midwinter, but in reality, the eddy activity is somehow suppressed. Specifically, $V^{\prime} T_{850}^{\prime}$ in midwinter is $\sim 85 \%$ of its peak value in spring, whereas the EGR in midwinter is $\sim 20 \%$ larger than in spring (Fig. 1f).

To investigate the typical structure of transient eddies, the local correlation in high-pass-filtered $850-\mathrm{hPa}$ fluctuations between meridional wind and temperature is calculated as $\operatorname{Corr}\left(V^{\prime}, T^{\prime}\right)=V^{\prime} T^{\prime} / \sqrt{V^{\prime} V^{\prime} \times T^{\prime} T^{\prime}}$. The correlation can be viewed as a measure of baroclinic structure of eddies. The western NP is a region of particularly high positive correlation and the correlation peaks in midwinter (Figs. 2a,b), when $V^{\prime} T_{850}^{\prime}$ exhibits its distinct minimum. This means that eddy baroclinic structure does not contribute to the distinct MWM of $V^{\prime} T_{850}^{\prime}$. Rather, the MWM of $V^{\prime} T_{850}^{\prime}$ is contributed primarily by high-pass-filtered temperature fluctuations (Fig. 2c). Actually, the fluctuations measured as RMS of $T^{\prime} T_{850}^{\prime}$ are particularly strong over the western NP with a distinct MWM (Fig. 2c). Its midwinter variance is less than $80 \%$ of those at the autumn/spring peaks (Fig. 2d), yielding more prominent suppression than its counterpart in $V^{\prime} T_{850}^{\prime}$.

The distinct MWM in $T^{\prime} T_{850}^{\prime}$ is likely to be contributed by diabatic heating. In fact, the background meridional temperature gradient also peaks in midwinter as seen in EGR and $V^{\prime} V_{850}^{\prime}$ exhibits no distinct MWM (Fig. 1), suggesting that meridional temperature advection associated with sub-weekly eddies should become strongest in midwinter. Actually, diabatic heating fluctuations measured as RMS of $Q^{\prime} Q_{850}^{\prime}$ exhibit their distinct early-winter peak and a clear MWM along its axis (Figs. 2e,f), which is located slightly to the south $\left(\sim 36^{\circ} \mathrm{N}\right)$ of the low-level storm-track axis marked by $V^{\prime} T_{850}^{\prime}$ maxima at individual longitudes. In the midwinter western NP, enhanced heat exchange with the underlying ocean and latent heat release both occurring under the strong cold advection behind individual cyclones can act to suppress lower-tropospheric temperature fluctuations (Chang 2001; Nakamura et al. 2004).

The poleward eddy heat flux is closely related to the upward wave-activity flux and thus the vertical structure of the MWM signature. Figure 3 shows zonal sections of the wave-activity flux defined by Takaya and Nakamura (2001) 
(a) corr V'T'850

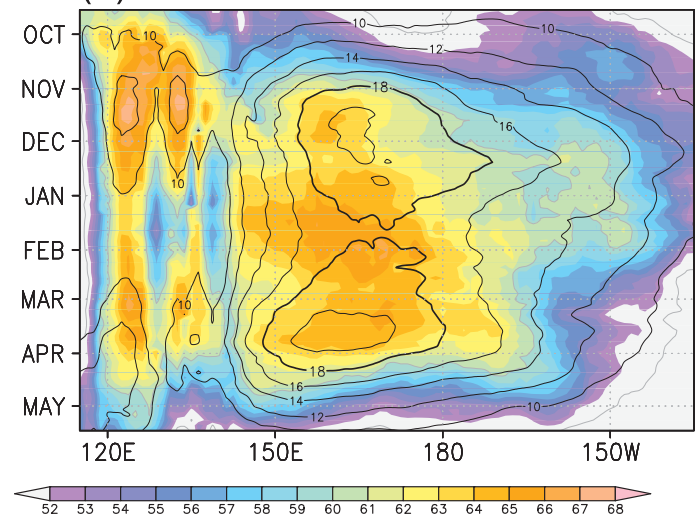

(c) T'T'850 RMS

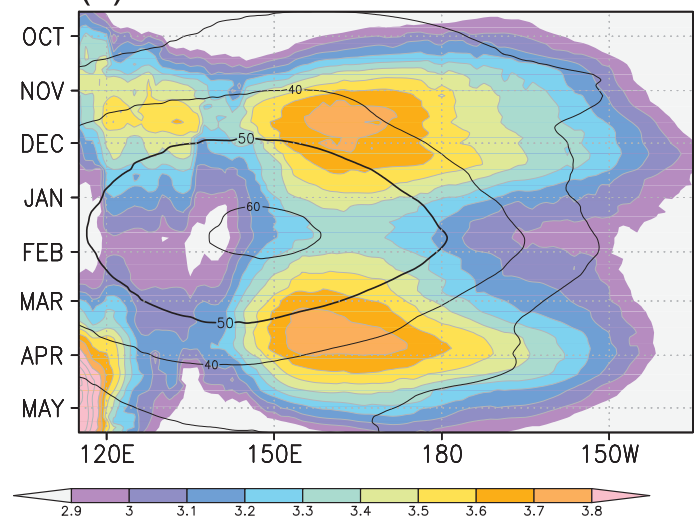

(e) Q'Q'850 RMS

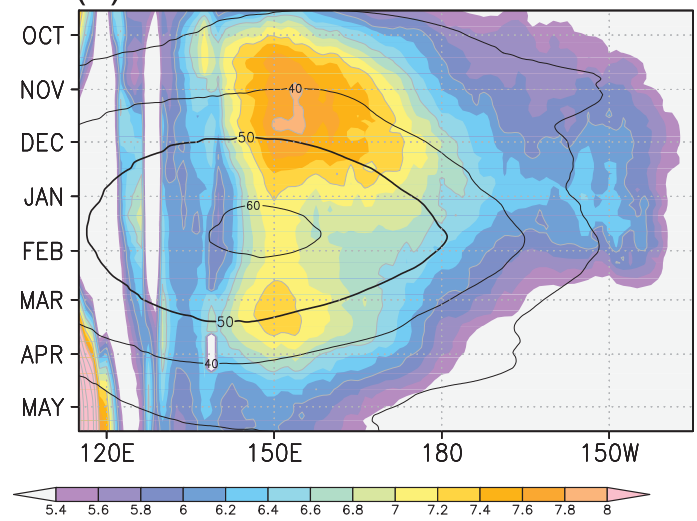

(b) corr V'T' 150-180E

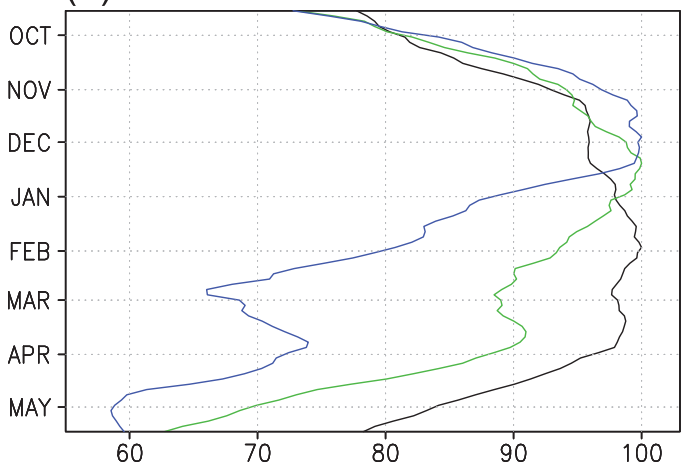

(d) T'T'850 150-180E

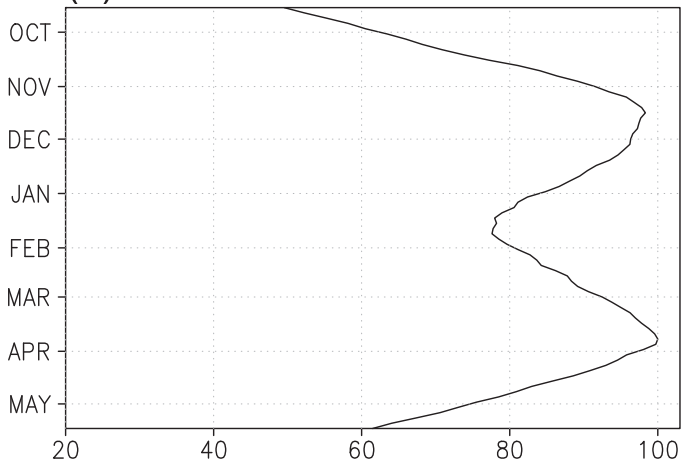

(f) Q'Q'850 140-170E

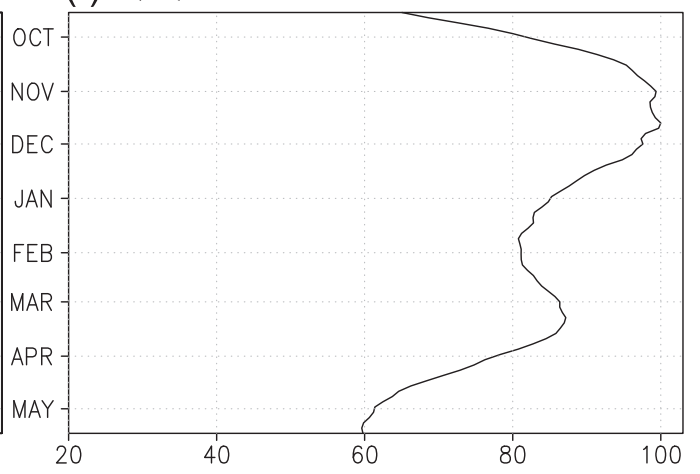

FIG. 2. (a) As in Fig. 1c, but for the correlation (\%) between $V^{\prime}$ and $T^{\prime}$ at $850 \mathrm{hPa}$ within $150^{\circ} \mathrm{E}-180^{\circ}$ around $V^{\prime} T_{850}^{\prime}$ maxima at individual longitudes. Contours indicate climatological-mean $V^{\prime} T_{850}^{\prime}$. (b) As in Fig. 1f, but for the correlations between $V^{\prime}$ and $T^{\prime}$ at 850 (black), 600 (green), and $400 \mathrm{hPa}$ (blue) within $150^{\circ} \mathrm{E}-180^{\circ}$. (c) As in (a), but for climatological-mean RMS of $T^{\prime} T_{850}^{\prime}$ (color; K) and $U_{300}\left(\mathrm{~m} \mathrm{~s}^{-1}\right)$. (d) As in (b), but for $T^{\prime} T_{850}^{\prime}$. (e) As in (c), but for RMS of $Q^{\prime} Q_{850}^{\prime}\left(\mathrm{K} \mathrm{day}^{-1}\right)$. (f) As in (b), but for $Q^{\prime} Q_{850}^{\prime}$ around the $Q^{\prime} Q^{\prime}$ axis within $140^{\circ}-170^{\circ} \mathrm{E}$.

on 4 December, 24 January, and 19 March, which climatologically correspond to the first peak, MWM, and second peak, respectively, of the NP storm-track activity. The flux plotted does not include the contribution of the term proportional to eddy phase speed. The eastward component of the flux in the upper troposphere therefore represents the downstream development of transient eddies pointed out by Chang (1993), and the flux is indeed dominantly eastward (Fig. 3). In addition, the flux is strongly upward from the lower- to midtroposphere over the western and central NP. In this region, eddy baroclinic growth is prominent as marked by high positive $V^{\prime}-T^{\prime}$ correlation (Fig. 2a), and abundant heat release from the ocean occurs in the cold season around the oceanic frontal zone to maintain near-surface baroclinicity (bottom panels in 
(a) 04Dec

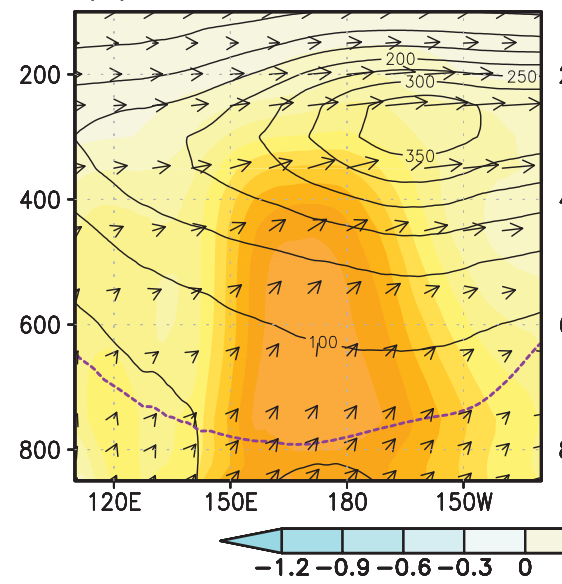

(b) 24Jan

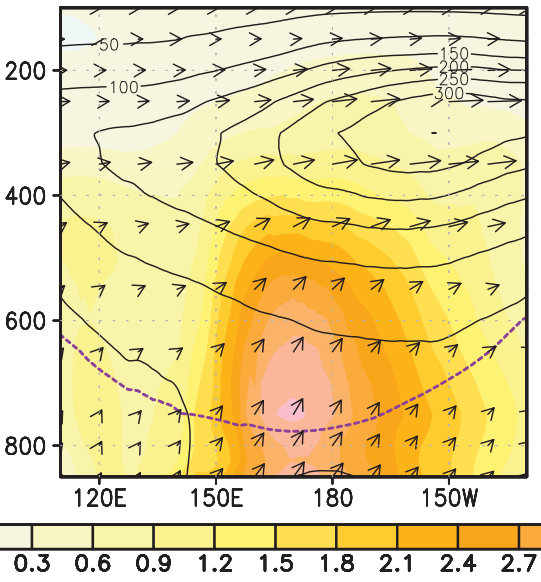

(c) 19 Mar

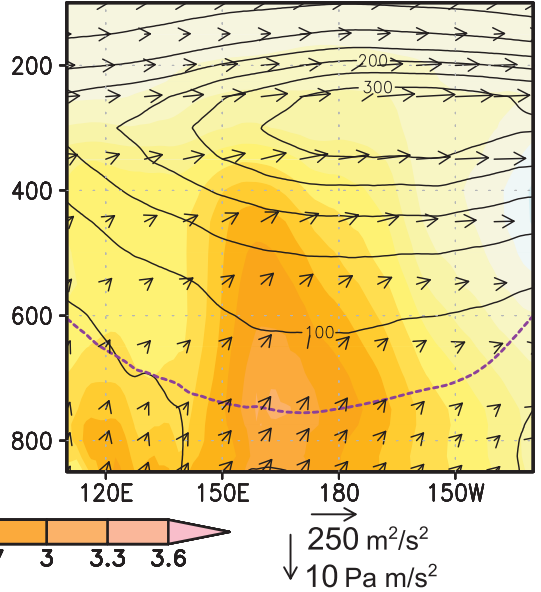

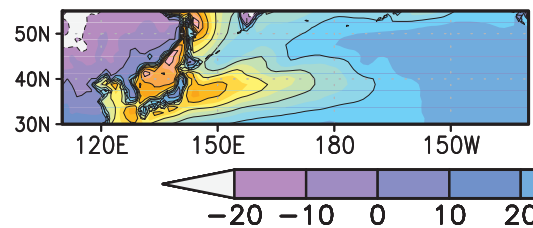
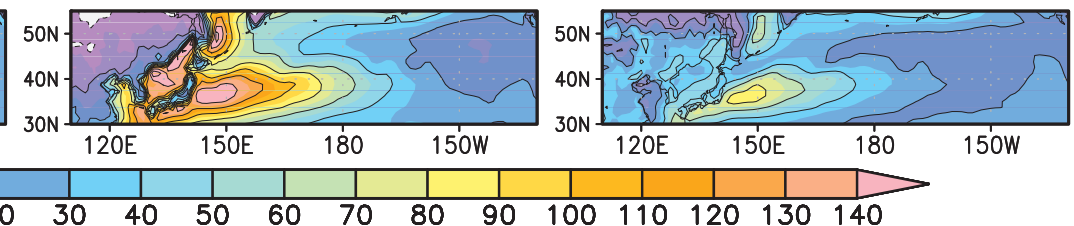

FIG. 3. (top) Zonal sections of climatological-mean wave-activity flux associated with sub-weekly transient eddies (vectors) defined by Takaya and Nakamura (2001) without the term proportional to eddy phase speed for (a) 4 Dec, (b) 24 Jan, and (c) 19 Mar. Colors indicate its vertical component $\left(\mathrm{Pa} \mathrm{m} \mathrm{s}^{-2}\right)$. Black contours denote climatological-mean EKE $\left(\mathrm{m}^{2} \mathrm{~s}^{-2}\right)$. Purple dotted lines denote levels at which the climatological-mean westerly wind speed is $10 \mathrm{~m} \mathrm{~s}^{-1}$ as an approximate measure of transient eddy phase speed. Quantities shown are meridionally averaged over $30^{\circ}-55^{\circ} \mathrm{N}$. (bottom) Horizontal maps of climatological-mean sensible heat flux from the ocean $\left(\mathrm{W} \mathrm{m}^{-2}\right)$.

Fig. 3; Hotta and Nakamura 2011). In the lower half of the troposphere, the upward wave-activity flux is strongest in midwinter (Fig. 3b), owing partly to the reduction of the stability parameter under the enhanced heat supply from the ocean (not shown). However, the upward flux at $\sim 400-\mathrm{hPa}$ is weaker in midwinter than in the shoulder seasons, when the flux exhibits a deeper structure and the strong flux reaches above the 400-hPa level (in color). In early winter, the strongest upward flux at $\sim 400-\mathrm{hPa}$ is consistent with a peak of $V^{\prime} T_{400}^{\prime}$ (not shown), which may contribute to the distinct upper-tropospheric MWM in $V^{\prime} V_{300}^{\prime}$ despite the unclear MWM in $V^{\prime} V_{850}^{\prime}$. In spring, the midtropospheric upward flux is rather confined to the upstream portion of the storm track $\left(\sim 160^{\circ} \mathrm{E}\right)$, which is consistent with the westward-extended maxima of $V^{\prime} V_{300}^{\prime}$ and EKE (contours in Fig. 3) into the Asian continent.

The covariance between high-pass-filtered diabatic heating and temperature $\left(Q^{\prime} T^{\prime}\right)$ contributes to diabatic energy generation of eddies (CQ in section 2). We focus on the midtroposphere, where $Q^{\prime} T^{\prime}$ is large mainly due to condensational heating. As evident in Fig. 4a, meridionally averaged $Q^{\prime} T_{600}^{\prime}$ around its local maxima is strongest over the western NP and peaks in early winter. When averaged zonally over $150^{\circ} \mathrm{E}-180^{\circ}$, it is suppressed in midwinter slightly ( $\sim 9 \%$ of the early winter peak, not shown), but its midwinter reduction is weaker than its counterpart of $V^{\prime} T_{850}^{\prime}$ or $T^{\prime} T_{850}^{\prime}$.

The covariance between high-pass-filtered (sign-reversed) pressure velocity and temperature $\left(-\omega^{\prime} T^{\prime}\right)$ contributes to the transfer from EAPE to EKE (ET in section 2). The covariance $-\omega^{\prime} T^{\prime}$ is prominent in the midtroposphere. Similar to $Q^{\prime} T_{600}^{\prime}$, meridionally averaged $600-\mathrm{hPa}-\omega^{\prime} T^{\prime}$ around its local maxima is strongest over the western NP and again peaks in early winter (Fig. 4c). Its midwinter amplitude is $90 \%-95 \%$ of the early winter peak (not shown), although this slight suppression is insufficient to account for a distinct minimum like that in $V^{\prime} T_{850}^{\prime}$.

\section{Energetics for the North Pacific storm track}

With the Eulerian statistics for sub-weekly transient eddies discussed above, we examine the climatological energetics for the NP storm track in the framework described in section $2 b$. As a typical midwinter case, distributions of vertically integrated climatological-mean energy and conversion/generation terms are shown in Fig. 5 for the 24 January, when the stormtrack activity shows its minimum climatologically. Vertically integrated climatological EKE and EAPE both exhibit their maxima along the NP storm track (Figs. 5a,b). The EAPE maximum is located upstream of the EKE maximum with smaller magnitude.

The barotropic energy conversion (CK) is negative around the jet exit region (Fig. 5c), where eddies are giving up EKE to the background westerlies. This is consistent with the westerly acceleration through vorticity flux by transient eddies represented as the diverging extended E-P flux (Trenberth 1986). In agreement with previous studies (e.g., Schemm and Rivière 2019), the baroclinic energy conversion (CP) is prominent in the storm-track core just east of Japan (Fig. 5d). This 
(a) Q'T'600

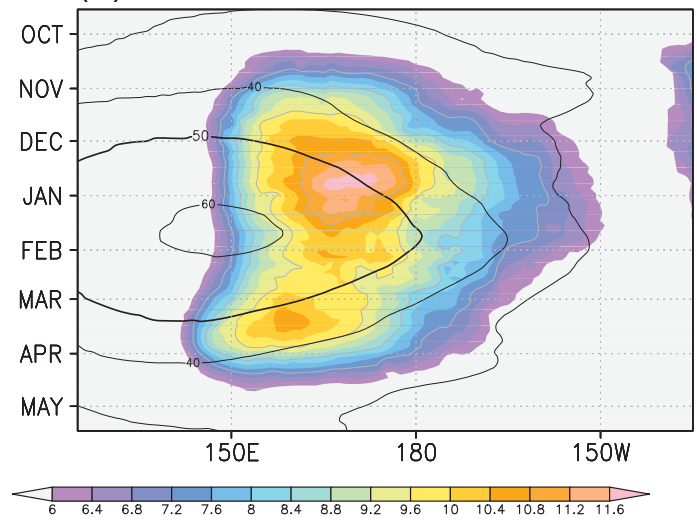

(c) $-\omega^{\prime} T^{\prime} 600$

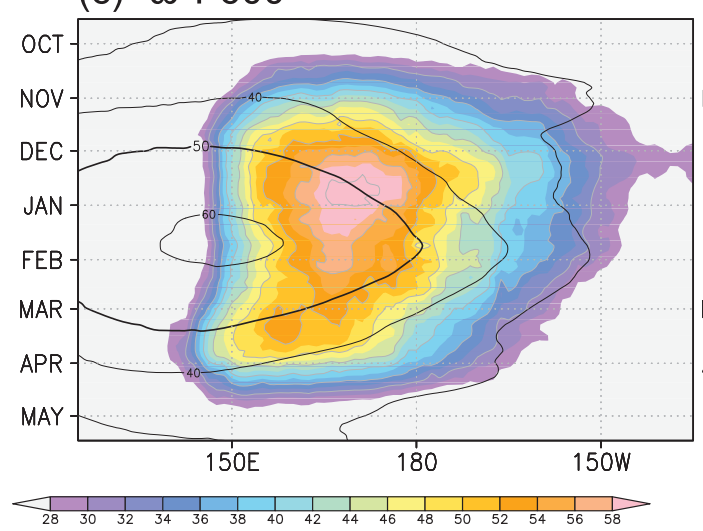

(b) corr Q'T' 150-180E

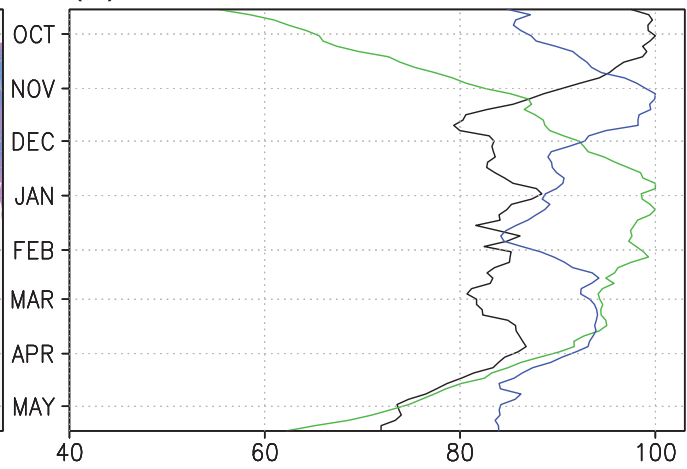

(d) corr $-\omega^{\prime} T^{\prime}$ 150-180E

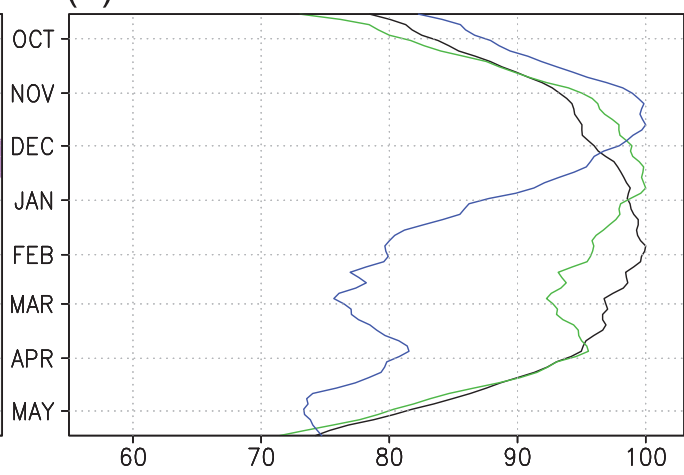

FIG. 4. (a) As in Fig. 1c, but for the covariance $\left(\mathrm{K}^{2}\right.$ day $\left.{ }^{-1}\right)$ between high-pass-filtered diabatic heating associated with precipitation $\left(Q^{\prime}\right)$ and temperature $\left(T^{\prime}\right)$ at $600 \mathrm{hPa}$. Contours denote climatological-mean $U_{300}\left(\mathrm{~m} \mathrm{~s}^{-1}\right)$. (b) As in Fig. 2b, but for $Q^{\prime} T_{850}^{\prime}$ (black), $Q^{\prime} T_{600}^{\prime}$ (green), and $Q^{\prime} T_{400}^{\prime}$ (blue). (c) As in (a), but for the covariance between high-pass-filtered (sign-reversed) pressure velocity $\left(-\omega^{\prime}\right)$ and temperature $\left(T^{\prime}\right)$ at $600 \mathrm{hPa}\left(\mathrm{Pa} \mathrm{K} \mathrm{s}^{-1}\right)$. (d) As in (b), but for $-\omega^{\prime} T_{850}^{\prime},-\omega^{\prime} T_{600}^{\prime}$, and $-\omega^{\prime} T_{400}^{\prime}$.

is due to the collocation of strongest poleward eddy heat flux and distinct meridional gradient of climatological-mean temperature (or large EGR) in the presence of the NP oceanic frontal zone (Hotta and Nakamura 2011) and the prominent Pacific jet. The CP maximum is located slightly upstream of the EAPE maximum. The amplitude of $\mathrm{CP}$ is much greater than that of CK. The APE generation through diabatic heating (CQ) is overall positive along the NP storm track (Fig. 5e), reflecting the positive $Q^{\prime}-T^{\prime}$ correlation in the free troposphere. The region of the positive CQ roughly collocates with the region of positive diabatic heating in the midtroposphere. The energy transfer (ET) from EAPE to EKE is largest in the western NP between the CP and EAPE maxima. The maximum value of ET is comparable to that of $\mathrm{CP}$ (Fig. 5f), indicating that most of the converted APE (CP) is transferred into EKE. The eastward energy flux (EF) is strongest along the storm track and deflected northward over the eastern NP (Fig. 5g), consistent with the distributions of EKE and EAPE (Figs. 5a,b).

Those energy conversion/generation terms are integrated horizontally over the NP domain $\left(20^{\circ}-65^{\circ} \mathrm{N}, 130^{\circ} \mathrm{W}-130^{\circ} \mathrm{E}\right)$ and vertically from the surface to $100 \mathrm{hPa}$, to evaluate the comprehensive energy budget for the NP storm track. Figure 6a shows the seasonal evolution of the three-dimensionally integrated EKE and EAPE. Both the integrated EKE and EAPE are reduced slightly in midwinter between their peaks in early winter and spring, in a manner consistent with the seasonality of $V^{\prime} V_{300}^{\prime}$ and $T^{\prime} T_{850}^{\prime}$ (Figs. 1a and 2d). This result verifies that spatially integrated eddy energy shows seasonal evolution similar to that of eddy statistics around the core region of the NP storm track.

Among the energy conversion/generation terms, CP and ET are much larger than the others (Fig. 6b), reflecting the baroclinic nature of sub-weekly eddies. Those terms peak in early winter before suppressed slightly in midwinter. The larger CP in winter than in autumn is consistent with both Chang (2001) and Zhao and Liang (2019). The most enhanced downstream extension of $V^{\prime} T_{850}^{\prime}$ in early winter (Fig. 1c) may be responsible for the early-winter peak of the spatially integrated CP. As shown later, CP is dominated by the component related to poleward eddy heat flux.

The climatological-mean barotropic conversion CK is systematically negative (Fig. 6b), indicating that EKE is converted into the mean westerlies, which is consistent with the acceleration of the midlatitude westerlies by transient eddies. 
(a) EKE

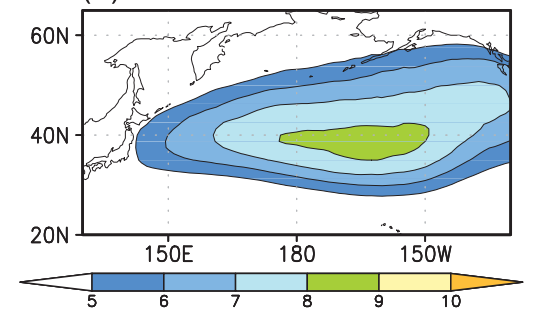

(b) EAPE

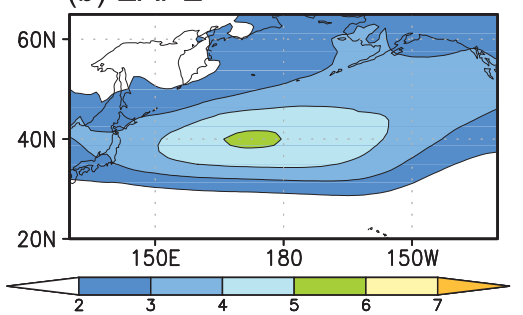

(c) $\mathrm{CK}$

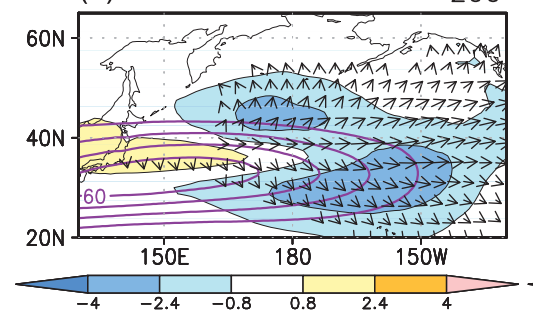

(f) ET

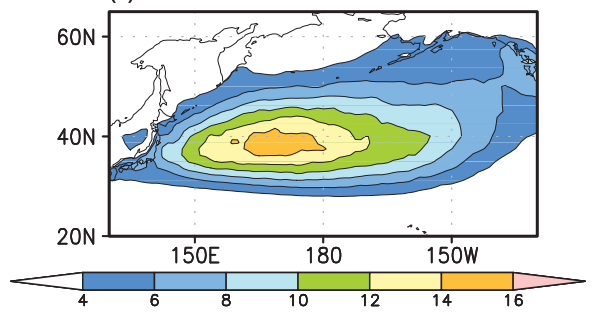

(d) $\mathrm{CP}$

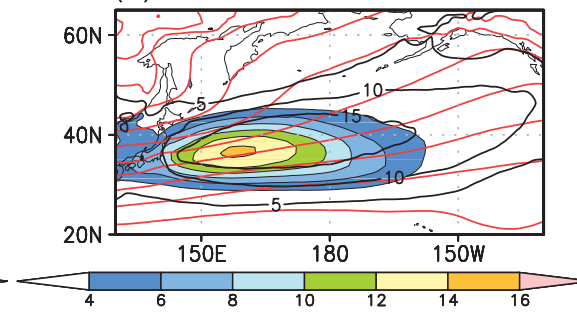

(e) $C Q$

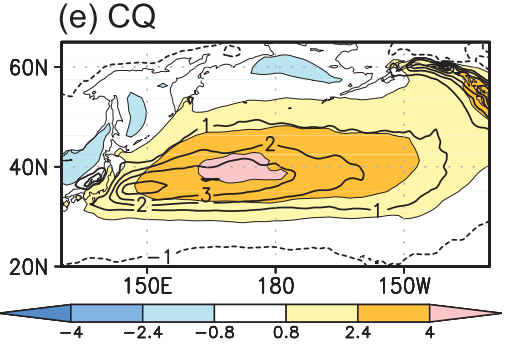

(g) $\mathrm{EF}$ $\overrightarrow{10}$

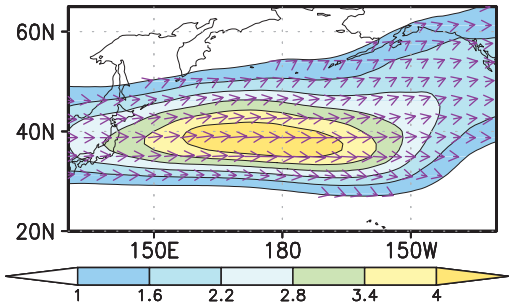

FIG. 5. Climatological energetics of sub-weekly eddies for 24 Jan. Vertically integrated climatological-mean (a) EKE and (b) EAPE $\left(10^{5} \mathrm{~J} \mathrm{~m}^{-2}\right)$. (c) Vertically integrated climatological-mean CK term (color; $\mathrm{W} \mathrm{m}^{-2}$ ), extended E-P flux at $300 \mathrm{hPa}\left(\mathrm{vectors} ; \mathrm{m}^{2} \mathrm{~s}^{-2}\right)$, and $U_{300}$ (purple contours; $\mathrm{m} \mathrm{s}^{-1}$ ). (d) Vertically integrated climatological-mean CP (color), $V^{\prime} T_{850}^{\prime}$ (black contour, $\mathrm{m} \mathrm{K} \mathrm{s}^{-1}$ ), and $T_{850}($ red contours; every $4 \mathrm{~K})$. (e) Vertically integrated climatological-mean CQ (color) and $Q_{700}$ (Black contours; every $1 \mathrm{~K}^{\text {day }}{ }^{-1}$ ). (f) Vertically integrated climatological-mean ET from EAPE to EKE. (g) Vertically integrated climatological-mean energy flux $\left(\right.$ vector; $10^{7} \mathrm{~J}_{\mathrm{m} \mathrm{s}}^{-1}$ ) and its amplitude (color; $10^{7} \mathrm{~J} \mathrm{~m} \mathrm{~s}^{-1}$ ).

More destructive (negative) CK in midwinter indicates stronger upper-tropospheric jet acceleration by transient eddies. The stronger negative feedback by eddies acting on a stronger westerly jet is consistent with results obtained through a dry quasigeostrophic model experiment by Robert et al. (2017).

The barotropic and baroclinic energy conversions from low-frequency variability to sub-weekly transients (CKLF and CPLF) are systematically negative and positive, respectively (Fig. 6b), yielding the slightly negative net energy conversion. Though relatively small, the magnitude of negative CKLF weakens around midwinter, acting to attenuate the midwinter suppression of the storm-track activity. The offsetting contributions between CKLF and CPLF are consistent with Lau and Nath (1991), who found that transient eddies along storm tracks act to reinforce monthly-mean circulation anomalies mainly through eddy vorticity fluxes while acting to weaken monthly-mean thermal anomalies. Differences in the relative amplitude of CKLF compared to CPLF between the present study and theirs can be attributable to different definitions of low-frequency variabilities.

The flux term EF is also negative throughout the cold season, indicating that eddy energy as a net is transported out of the NP storm track. It should be noted that there is still a relatively large positive remainder $\left(\sim 10^{14} \mathrm{~W}\right.$ in winter $)$ in the energy budget of transient eddies, which is consistent with the previous studies (e.g., Chang et al. 2002). The remainder may be primarily due to dissipation associated with surface friction and gravity waves induced by orography, which was found to be quite effective (with time scale of less than 1 day) in the planetary boundary layer (Klinker and Sardeshmukh 1992). ${ }^{2}$

By definition, the energy conversion/generation terms are proportional to the squared amplitude of transient eddies. To avoid the dependence of those terms on eddy amplitude, it is vitally important to evaluate their normalized rates $(\lambda)$ based on (4). Figure $6 \mathrm{c}$ indicates that $\lambda_{\mathrm{CP}}$ (red line) is much higher than $\lambda_{\mathrm{CK}}, \lambda_{\mathrm{CQ}}, \lambda_{\mathrm{EF}}, \lambda_{\mathrm{CKLF}}$, and $\lambda_{\mathrm{CPLF}}$. We thus confirm that baroclinic eddy growth, especially through the poleward eddy heat

\footnotetext{
${ }^{2}$ The contributions from surface friction and gravity waves can be approximately estimated through parameterized surface momentum fluxes provided by JRA-55. For example, a horizontally averaged monthly-mean value of the sum of those fluxes multiplied by $10-\mathrm{m}$ winds is $\sim 1.2 \times 10^{14} \mathrm{~W}$ within the domain $\left(130^{\circ} \mathrm{E}-130^{\circ} \mathrm{W}, 20^{\circ}-65^{\circ} \mathrm{N}\right)$ in January 2017.
} 
(a) Energy

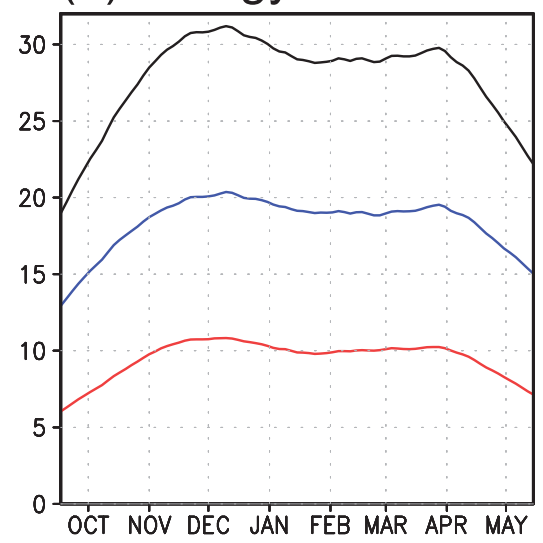

(b) Power

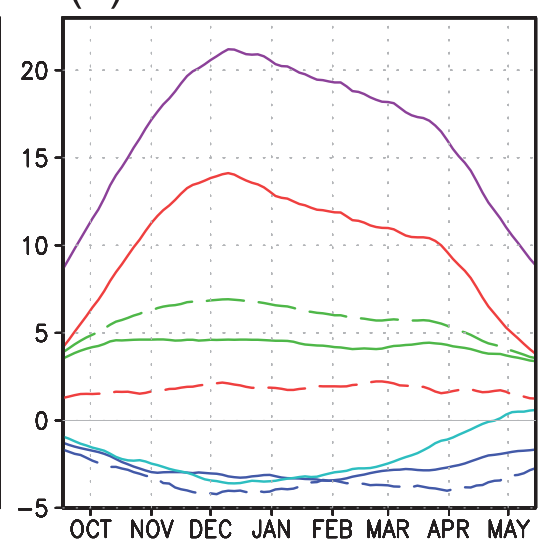

(c) Normalized rate

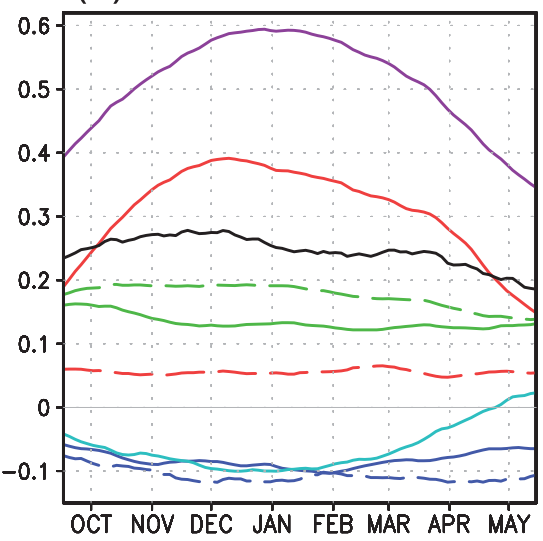

FIG. 6. (a) Climatological-mean seasonal evolution of EKE (blue), EAPE (red), and EKE + EAPE (black) integrated three-dimensionally over the NP $\left(10^{18} \mathrm{~J}\right)$. A tick mark on the abscissa represents the first day of a given calendar month. (b) As in (a), but for three-dimensionally integrated power of CK (solid blue), CKLF (dashed blue), CP (solid red), CPLF (dashed red), CQ (solid green), CQ associated only with precipitation (dashed green), EF (light blue), and ET (purple). Units: $10^{13} \mathrm{~W}$. (c) As in (b), but for $\lambda_{\mathrm{CK}}$ (solid blue), $\lambda_{\mathrm{CKLF}}$ (dashed blue), $\lambda_{\mathrm{CP}}$ (solid red), $\lambda_{\mathrm{CPLF}}$ (dashed red), $\lambda_{\mathrm{CQ}}$ (solid green), $\lambda_{\mathrm{CQ}}$ associated only with precipitation (dashed green), $\lambda_{\mathrm{EF}}($ light blue), and $\lambda_{\mathrm{ET}}$ (purple). Black line denotes $\lambda_{\text {Tot }}$ relevant to the budget of EKE + EAPE (viz., CK + CP + CQ + EF + CKLF + CPLF). Units: day ${ }^{-1}$.

flux (Fig. 7a), is of primary importance for maintaining the NP storm-track activity. The $\lambda_{\mathrm{CP}}$ is highest in early winter and then reduced somewhat in midwinter and further into early spring, which is consistent with the early-winter peak of the $V^{\prime}-T^{\prime}$ correlation in the mid and upper troposphere (Fig. 2b). Interestingly, $\lambda_{\mathrm{ET}}$ (purple line) maximizes in January, indicating that the internal conversion from EAPE to EKE is most effective in midwinter. It is mainly contributed to by the lower and midtropospheric $E T$, as seen in the $\omega^{\prime}-T^{\prime}$ correlation (Fig. 4d). By contrast, $\lambda_{\mathrm{ET}}$ (light blue line) and $\lambda_{\mathrm{CK}}$ (blue line) are more destructive in early and midwinter than in spring, while $\lambda_{\mathrm{CQ}}$ (green line) is nearly constant throughout the cold season. The midtropospheric $Q^{\prime}-T^{\prime}$ correlation exhibits its midwinter maximum (green line in Fig. 4b), but its effect is offset by the MWM of the corresponding correlation in the upper troposphere (blue line) and autumn peak of the lower-tropospheric counterpart (black line) as well as the effect by vertical diffusion and radiative processes, as shown below.

When $\mathrm{CP}$ is combined with the other processes $(\mathrm{CK}, \mathrm{CQ}$, $\mathrm{EF}, \mathrm{CKLF}$, and CPLF), the resultant $\lambda_{\text {Tot }}$ (black line in Fig. 6c) for the storm-track energetics shows a fairly apparent midwinter suppression. This result suggests that processes other than $\mathrm{CP}$, especially $\mathrm{CK}$ and $\mathrm{EF}$, are likely to contribute to the formation of the MWM, particularly to the early-spring recovery. The $\lambda_{\mathrm{CQ}}$ associated only with precipitation is kept nearly constant from early to midwinter (green dashed line) before slightly reduced into spring.

In the following, some of the conversion/generation terms are investigated in more detail. Decomposition of $\lambda_{\mathrm{CP}}$ into the two components related to the zonal heat flux $\left\{\left(R / p S_{p}\right)\left[-\left(u^{\prime} T^{\prime}\right)_{C}\left(d T_{c} / d x\right)\right]\right\}$ and meridional heat flux $\left\{\left(R / p S_{p}\right)\left[-\left(v^{\prime} T^{\prime}\right)_{C}\left(d T_{c} / d y\right)\right]\right\}$ reveals that the latter dominates over the former throughout the cold season (red lines in Fig. 7a). Although minor, the former turns to positive in midwinter. Similarly, decomposition of $\lambda_{\mathrm{CK}}$ into the "zonal" $\left\{\left[\left(v^{\prime 2}-u^{\prime 2}\right)_{C} / 2\right]\left[\left(d u_{c} / d x\right)-\left(d v_{c} / d y\right)\right]\right\}$ and "meridional" $\left\{-\left(u^{\prime} v^{\prime}\right)_{C}\left[\left(d u_{c} / d y\right)+\left(d v_{c} / d x\right)\right]\right\}$ components reveals that the latter contributes to the negative $\lambda_{\mathrm{CK}}$ constantly throughout the cold season (blue dotted line in Fig. 7a), while the former exhibits apparent seasonality and becomes comparable with the latter only in midwinter (blue dashed line). From the viewpoint of energetics, the midwinter peak of the destructive feedback through eddy momentum flux is thus mainly due to the "zonal" component of $\lambda^{\mathrm{CK}}$ operative under the strongest jet confluence/ diffluence but not due to the "meridional" component acting on the narrow westerly jet as suggested by the "barotropic governor" mechanism. In midwinter, meridional shear of the climatological-mean Pacific jet is certainly the strongest, but it does not necessary lead to enhanced distortion of eddies favorable for the "barotropic governor" mechanism. In fact, the positive $U^{\prime}-V^{\prime}$ correlation to the south of the jet axis does not maximize in midwinter, in contrast to the midwinter peak of the negative $U^{\prime}-V^{\prime}$ correlation to the north (not shown). Rather, the negative "zonal" component is dominant around the jet exit region with its midwinter peak. It should be attributed to the strongest diffluence of the Pacific jet around its exit in midwinter (Figs. 8a-c), because eddy anisotropy $\left[\left(V^{\prime} V^{\prime}-U^{\prime} U^{\prime}\right) /\left(V^{\prime} V^{\prime}+U^{\prime} U^{\prime}\right)\right]$ minimizes in midwinter around the jet core region (not shown). In fact, eddy meridional wind fluctuations tend to undergo strong damping in midwinter by anomalous meridional advection of meridional momentum induced under the enhanced background diffluence with positive $\partial V_{\mathrm{c}} / \partial y$ (in addition to prominent negative $\left.\partial U_{\mathrm{c}} / \partial x\right)$. In the jet exit region, negative $\mathrm{CK}$ is stronger to the north of the jet axis in midwinter and spring, while in early winter it is larger to the south of the jet axis whose southwest-northeast tilt tends to be seasonally enhanced (Figs. 8d-f). 
(a) CK\&CP

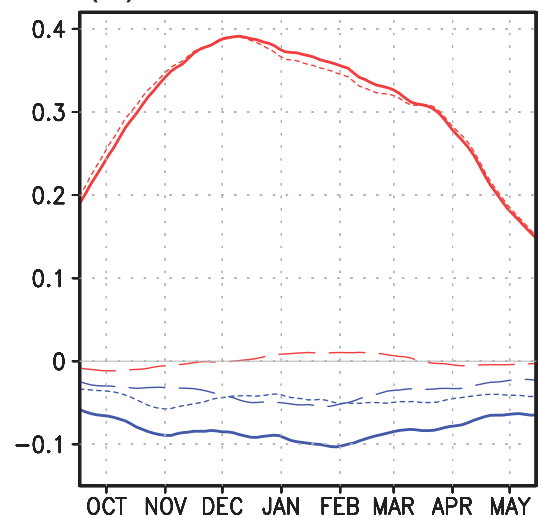

(b) CQ components

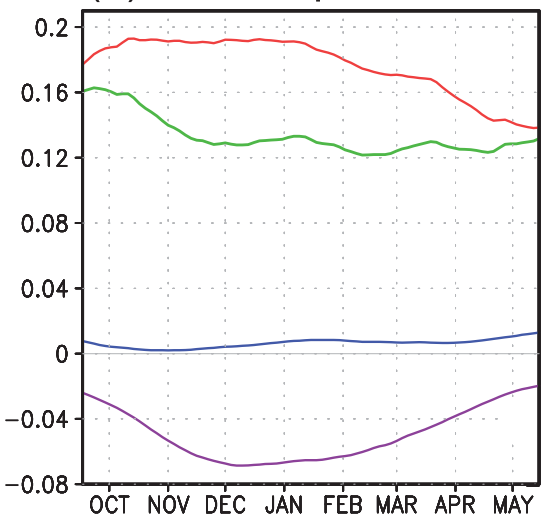

(c) Total EF

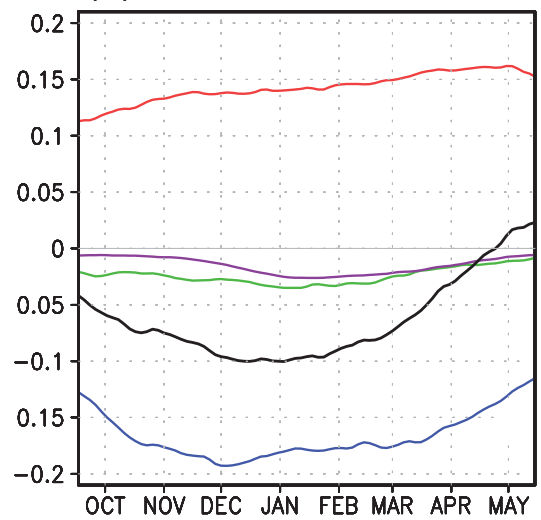

(d) Advective EF

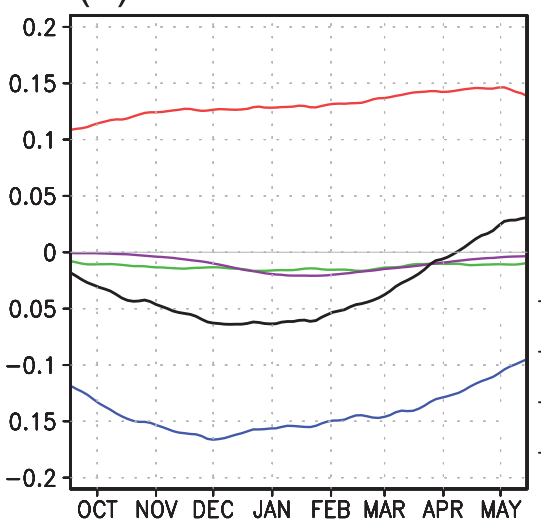

(e) Eddy EF

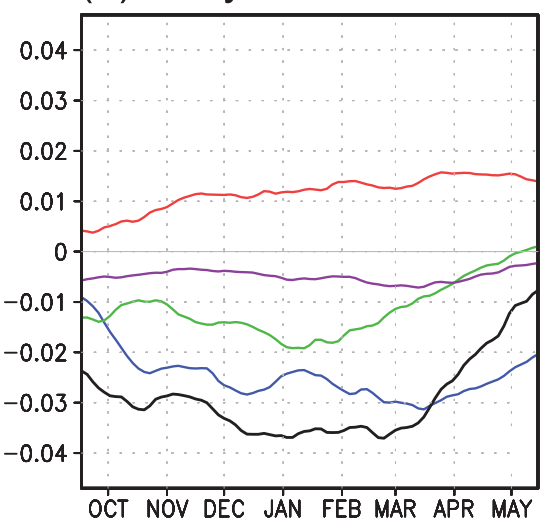

FIG. 7. (a) As in Fig. 6c, but for "zonal" (dashed lines), "meridional” (dotted lines), and total (solid lines) components of $\lambda_{\mathrm{CK}}$ (blue) and $\lambda_{\mathrm{CP}}(\mathrm{red})$. See the text for details. (b) As in Fig. 6b, but for the total $\lambda_{\mathrm{CQ}}$ (green), $\lambda_{\mathrm{CQ}}$ associated solely with precipitation (red), vertical diffusion (purple), and radiative processes (blue). (c) As in Fig. 6c, but for the total energy fluxes through the western (red), eastern (blue), southern (purple), and northern (green) boundaries. Black line denotes the net total energy flux. Positive (negative) values mean inward (outward) fluxes. (d),(e) As in (c), but for energy flux term associated solely with energy advected by climatological-mean flow in (d) and eddy geopotential flux in (e).

The total $\lambda_{\mathrm{CQ}}$ is modestly positive throughout the cold season (green line in Fig. 7b). Consistent with the climatological-mean midtropospheric $Q^{\prime} T^{\prime}$ (Fig. 4a), $\lambda_{\mathrm{CQ}}$ associated solely with precipitation and the corresponding latent heat release peaks in early winter (red line in Fig. 7b). It is systematically greater than the total $\lambda_{\mathrm{CQ}}$, because the latter includes dominant thermal damping through heat exchanges with the underlying ocean (purple line in Fig. 7b). This damping effect is strongest in early winter over the relatively warm ocean, acting to weaken the early-winter peak of $\lambda_{\mathrm{CQ}}$ associated only with precipitation. Finally, $\lambda_{\mathrm{CQ}}$ associated solely with radiative processes is almost negligible if integrated three-dimensionally (blue line in Fig. 7b).

The seasonality of CQ is overall consistent with Chang (2001), who utilized a rather coarse-resolution AGCM experiment, and with Zhao and Liang (2019), who evaluated it as the residual of the EAPE equation. Compared with our result, a slightly stronger early-winter peak of CQ found by Zhao and Liang (2019) may be due to the different latitude of the northern boundary of the analysis domain and to their vertical integration above the $1000-\mathrm{hPa}$ level. The larger total
CQ in October than in midwinter especially over the western NP shown by Chang (2001) has been confirmed by the integration only over the western NP domain (not shown). The present study utilizes the individual diabatic heating components obtained in a more recent reanalysis data (JRA-55). Although the results depend on a particular forecast model and data assimilation system, the evaluation of the individual heating components has become possible by taking advantage of the reanalysis data.

The net total $\lambda_{\mathrm{EF}}$ can be decomposed into the contributions from energy fluxes passing through the four (western, eastern, northern, and southern) lateral boundaries and further into the advective and eddy flux components (Figs. 7c-e). In the net total $\lambda_{\mathrm{EF}}$ (Fig. 7c), the energy fluxes through the western and eastern boundaries (red and blue lines, respectively) are largely canceled out. Nevertheless, the flux out of the eastern boundary is systematically larger, especially in early winter, when the connection into the Atlantic storm track is most obvious (not shown). Both the energy inflow through the western boundary and outflow through the eastern boundary 
(a) CKx 04Dec

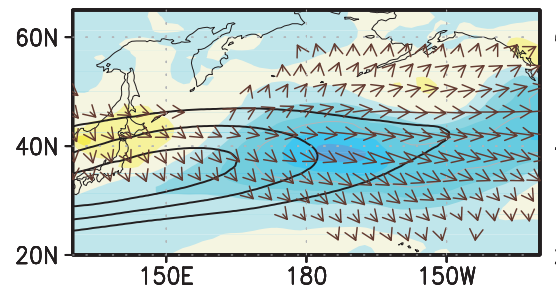

(d) CKy 04Dec

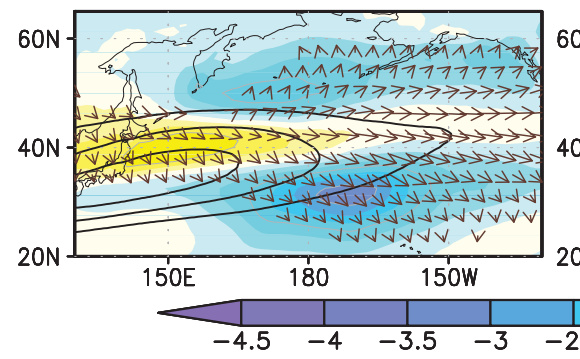

(b) CKx 24Jan

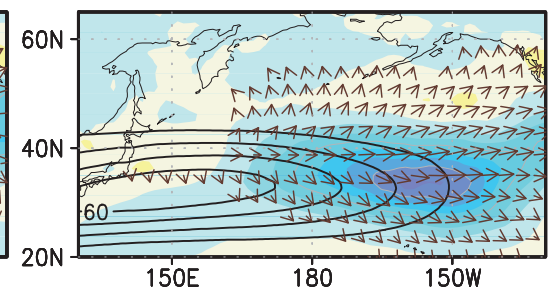

(e) CKy 24Jan

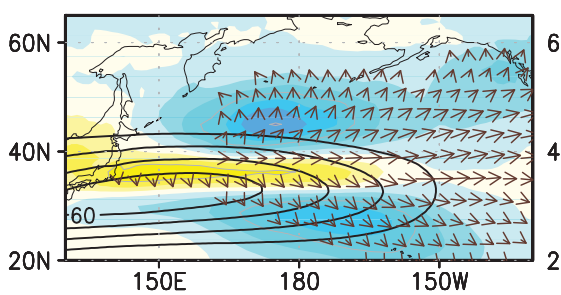

(c) CKx 19Mar

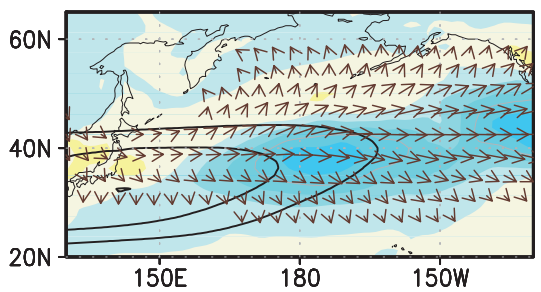

(f) CKy 19Mar

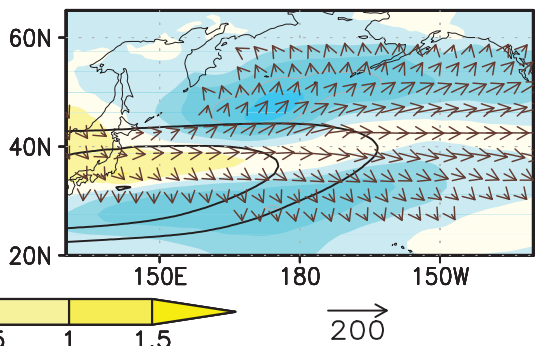

FIG. 8. (a)-(c) Vertically integrated climatological-mean "zonal" component of the CK term (color; $\mathrm{W} \mathrm{m}^{-2}$ ), extended E-P flux at 300 $\mathrm{hPa}$ (vectors; $\mathrm{m}^{2} \mathrm{~s}^{-2}$ ), and $U_{300}$ (black contours; $\mathrm{m} \mathrm{s}^{-1}$ ) for (a) 4 Dec, (b) 24 Jan, and (c) 19 Mar, respectively. (d)-(f) As in (a)-(c), respectively, but for "meridional" component of the CK term.

are mostly due to the advective effect by the mean westerlies (Fig. 7d). Still, the net zonal energy influx contributes to the MWM of the net $\lambda_{\mathrm{EF}}$, especially for the spring recovery (light blue line in Fig. 6c). The corresponding energy fluxes through the southern and northern boundaries (purple and green lines, respectively, in Fig. 7c) are both relatively weak and outward, and they tend to peak in midwinter. Unlike the zonal energy fluxes, the eddy geopotential flux contributes substantially to the meridional energy outflow primarily through the northern boundary (Figs. 7d,e). Overall, the net contributions from eddies and the mean flow are comparable to the meridional energy outflow.

Recently, Zhao and Liang (2019) investigated individual energy conversion/generation terms in the energetics associated with the NP storm track, but their evaluations included direct contributions from eddy amplitude itself. Chang (2001) evaluated some energy conversion rates and their "growth rate" independent of eddy amplitude. Their evaluation was, however, conducted for local conversion/generation terms and only with EKE, which may not necessarily lead to full delineation of the maintenance mechanisms for the NP stormtrack activity. This is because total eddy energy is better represented as the sum of EKE and EAPE, the latter of which is replenished mainly through the baroclinic conversion. In addition, the MWM is a basin-scale phenomenon, and therefore the three-dimensionally integrated energy budget analysis is required. Recently, Schemm and Rivière (2019) evaluated the efficiency of $\mathrm{CP}$, in which baroclinic conversion rate is normalized locally by the product of total eddy energy and the magnitude of background baroclinicity. It is certainly advantageous for measuring the ability of eddies themselves in converting energy, though without representing an actual conversion rate of a given process for eddy energy. We point out that their evaluation was performed only for $\mathrm{CP}$ over a specific domain in the western NP. The present study performs a comprehensive evaluation of $\lambda$ for each of the energy conversion/generation terms based on the three-dimensionally integrated statistics for the entire NP storm track, which can provide straightforward information about the ability of a given process to act against damping and dissipating processes with a dimensional time scale. We have revealed that $\lambda_{\text {Tot }}$, in which all the processes are combined, is indeed reduced in midwinter in a manner consistent with the MWM of the storm-track activity, although its spring recovery is marked only as subtle peak of $\lambda_{\text {Tot }}$ compared to the eddy energy. These results are consistent with Hadas and Kaspi (2021), who showed, via tracking of upper- and lower-level eddy activity, a faster barotropization of the westward tilt of baroclinic eddies when the jet is stronger. This provides a mechanism leading to the energy conversions demonstrated in this section.

\section{Long-term modulations of the MWM}

Nakamura et al. (2002) found that the MWM of the NP storm-track activity became less distinct in a recent period after 1986 than in the earlier period. Figure 9 shows interannual variability of 5-yr running-mean storm-track activity including its seasonality. In agreement with Nakamura et al. (2002), the MWM of $V^{\prime} V_{300}^{\prime}$ was prominent in the 1960s and from the late 1970s to mid-1980s (Fig. 9a), and in the latter the MWM was distinct also in $V^{\prime} T_{850}^{\prime}$ (Fig. 9b). In these two periods, upper-level westerlies were prominently strong both in the jet core region (Fig. 9b) and downstream (Fig. 9a). After the mid-1980s, the midwinter upper-level westerlies somewhat weakened, and concurrently each of $V^{\prime} V_{300}^{\prime}$ and 
(a) V'V'300 180-150W

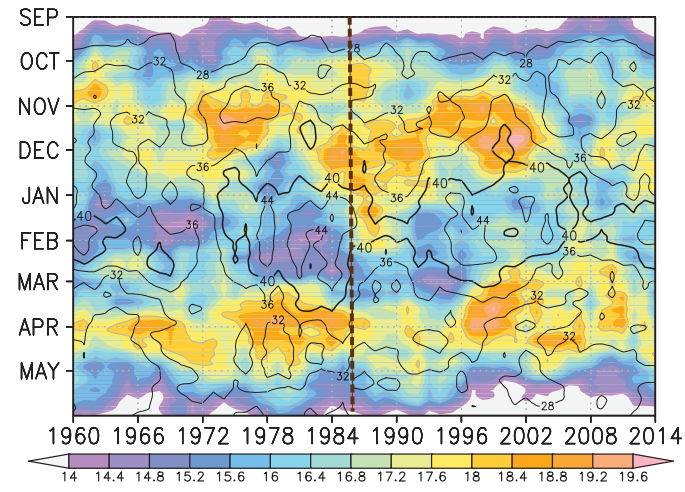

(b) V'T'850 150-180E

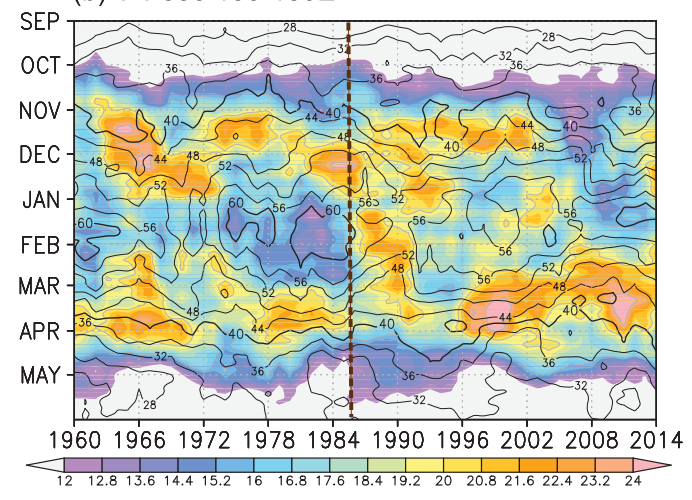

FIG. 9. (a) RMS of 5-yr mean of 31-day running mean $V^{\prime} V_{300}^{\prime}$ (color; $\mathrm{m} \mathrm{s}^{-1}$ ) and $U_{300}$ (contours; $\mathrm{m} \mathrm{s}^{-1}$ ) averaged meridionally for 9 grids whose center is at the maximum within $25^{\circ}-60^{\circ} \mathrm{N}$ at each longitude and then zonally over $180^{\circ}-150^{\circ} \mathrm{W}$. Dotted vertical lines mark the transition from $1985 / 86$ to $1986 / 87$. Labels on the abscissa indicate years of December. (b) As in (a), but for $V^{\prime} T_{850}^{\prime}\left(\right.$ color; $\left.\mathrm{m} \mathrm{K} \mathrm{s}^{-1}\right)$ and $U_{300}\left(\mathrm{~m} \mathrm{~s}^{-1}\right)$ averaged for $150^{\circ} \mathrm{E}-180^{\circ}$.

$V^{\prime} T_{850}^{\prime}$ increased to yield weaker or even almost no MWM. The transition from 1985/86 to 1986/87 (indicated by dotted lines in Fig. 9) was quite distinct in those two eddy statistics and the upper-level westerlies, as pointed out by Nakamura et al. (2002). In a more recent period, especially around 2010, storm-track activity, especially $V^{\prime} T_{850}^{\prime}$, from autumn to early winter has weakened slightly. Since the late 1990s, by contrast, spring peaks of both $V^{\prime} T_{850}^{\prime}$ and $V^{\prime} V_{300}^{\prime}$ have become more prominent than their early-winter peaks.

In recognition of the distinct transition from 1985/86 to 1986/87, climatological-mean fields for 1958/59-1985/86 and 1986/87-2016/17 are compared in the following to highlight the long-term modulations of the MWM of the NP stormtrack activity. Figure 10 compares the climatological-mean seasonal evolutions of RMS $V^{\prime} V_{300}^{\prime}$ meridionally averaged around its maximum for each longitude between the earlier and later periods. Compared with its counterpart for the entire 60-yr period (Fig. 1d), the MWM in the earlier period (before 1987) is even more prominent over the entire NP (Fig. 10a) with $V^{\prime} V_{300}^{\prime}$ in midwinter being less than $70 \%$ of its spring peak (Fig. 10c). Conversely, the MWM is less evident for the later period (after 1986) under the slightly weaker westerly jet around its core (Fig. 10b). The enhanced midwinter eddy activity in the upper troposphere is consistent with greater upward wave-activity flux from the lower- to midtroposphere (not shown). The midwinter storm-track activity increases by $\sim 20 \%$ from the earlier period, exceeding $80 \%$ of the seasonal maximum (Fig. 10d). Compared to the earlier period, the occurrence of the first peak in the later period delays into mid-December and its amplitude is slightly larger. Westward extension of the NP storm track around the spring peak is less prominent than in the earlier period, and its core is thus shifted downstream (Fig. 10b). Over the eastern NP, a secondary maximum of $U_{300}$ occurs simultaneously $\left(30 \mathrm{~m} \mathrm{~s}^{-1}\right.$ contour in Fig. 10b), and its secondary maximum in spring becomes stronger in the later period.

Similar to $V^{\prime} V_{300}^{\prime}$, the MWM of $V^{\prime} T_{850}^{\prime}$ is more prominent in the earlier period (Fig. 11), while the minimum almost vanishes in the later period (Fig. 11e). We confirm that the difference in midwinter $V^{\prime} T_{850}^{\prime}$ as well as that in $V^{\prime} V_{300}^{\prime}$ is statistically significant (not shown). Likewise, $V^{\prime} V_{850}^{\prime}$ underwent essentially the same interdecadal change (Figs. 11b,f). An even more pronounced MWM signature is found in $T^{\prime} T_{850}^{\prime}$ during the earlier period (with reduction by more than $\sim 30 \%$; Fig. 11c) than in the entire period (Fig. 2). In the later period (Fig. 11g), the MWM is still recognizable but has become somewhat less distinct, while the spring peak has become more prominent. Meanwhile, the $850-\mathrm{hPa} V^{\prime}-T^{\prime}$ correlation shows no midwinter maximum or minimum in the earlier period (Fig. 11d), whereas it exhibits a slight midwinter maximum in the later period (Fig. 11h). The maximum correlation in midwinter suggests that the vertical structure of transient eddies becomes more baroclinic, and thus more favorable for the CP than in the shoulder seasons. These results indicate that all the components related to $V^{\prime} T_{850}^{\prime}$ (i.e., $V^{\prime} V_{850}^{\prime}, T^{\prime} T_{850}^{\prime}$, and the correlation) contribute to the weakening of its MWM in the later period.

Applying the same procedures as in section 4, we evaluate the energetics of sub-weekly transient eddies along the NP storm track separately for the earlier and later periods. In the earlier period, there are more apparent MWM signals in both spatially integrated EKE and EAPE (Fig. 12a) compared to those for the entire period (Fig. 6a), while the corresponding signals become ambiguous in the later period owing mainly to the enhanced midwinter eddy activity (Fig. 12b). This is consistent with the abovementioned results based on the Eulerian statistics.

As illustrated in Figs. 12c and 12d, the normalized rates of energy conversion/generation terms evaluated with total eddy energy (EKE + EAPE) separately for the two periods exhibit their long-term modulations. In the earlier period, $\lambda_{\mathrm{CP}}$ (red line in Fig. 12c) undergoes a clearer midwinter reduction, leading to a noticeable midwinter suppression (with a slight minimum) of $\lambda_{\text {Tot }}$ (black line). In the later period, by contrast, the midwinter reduction of $\lambda_{\mathrm{CP}}$ after its early-winter peak is weaker, yielding no MWM of $\lambda_{\text {Tot }}$ (Fig. 12d). The weaker 
(a) $1958 / 59-1985 / 86$

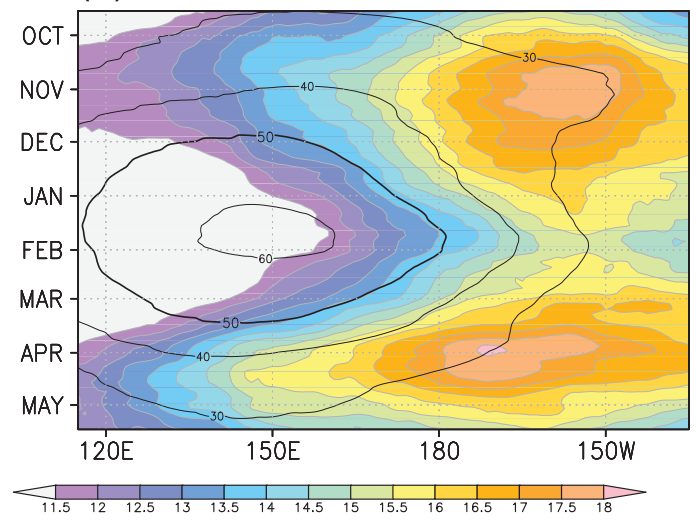

(c) $1958 / 59-1985 / 86$

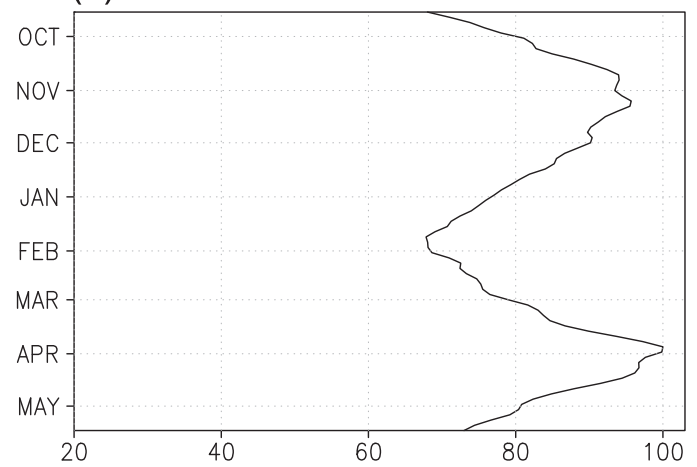

(b) $1986 / 87-2016 / 17$

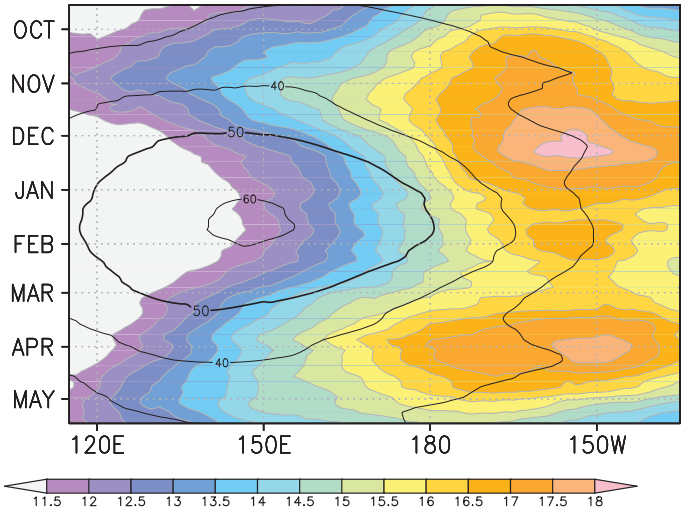

(d) $1986 / 87-2016 / 17$

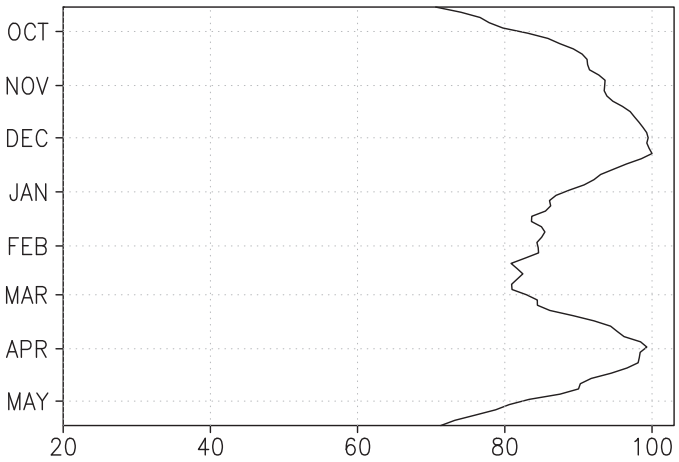

FIG. 10. (a),(b) As in Fig. 1a, but for the periods of 1958/59-1985/86 and 1986/87-2016/17, respectively. (c),(d) As in Fig. 1d, but for the periods of 1958/59-1985/86 and 1986/87-2016/17, respectively.

midwinter reduction of $\lambda_{\mathrm{CP}}$ for the later period is consistent with the more apparent midwinter maximum of the $V^{\prime}-T^{\prime}$ correlation than in the earlier period (Figs. 11d,h). Interestingly, the negative $\lambda_{\mathrm{CK}}$ (blue lines in Figs. 12c,d) from early to midwinter as an indication of eddy acceleration of the mean westerlies is enhanced in the later period, to which both the "zonal" and "meridional" components contribute (not shown). This indicates that the interdecadal enhancement of (a) V'T'850 1958-1985

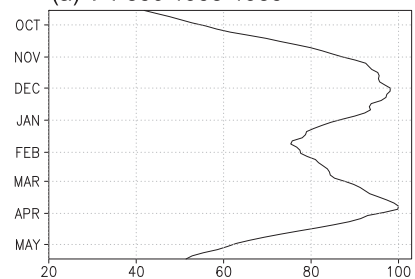

(e) V'T'850 1986-2016

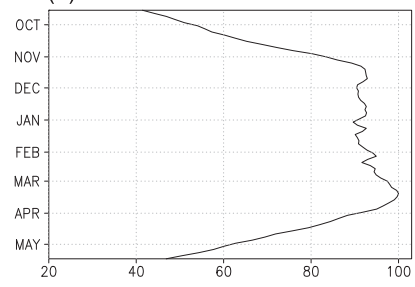

(b) V'V'850

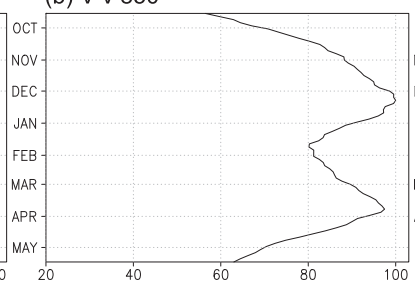

(f) V'V'850

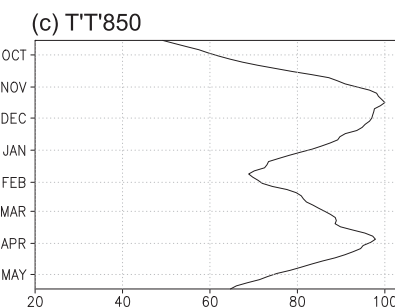

(g) T'T'850

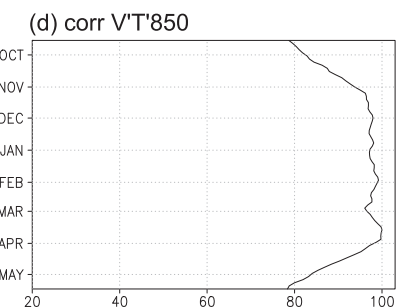

(h) corr V'T'850
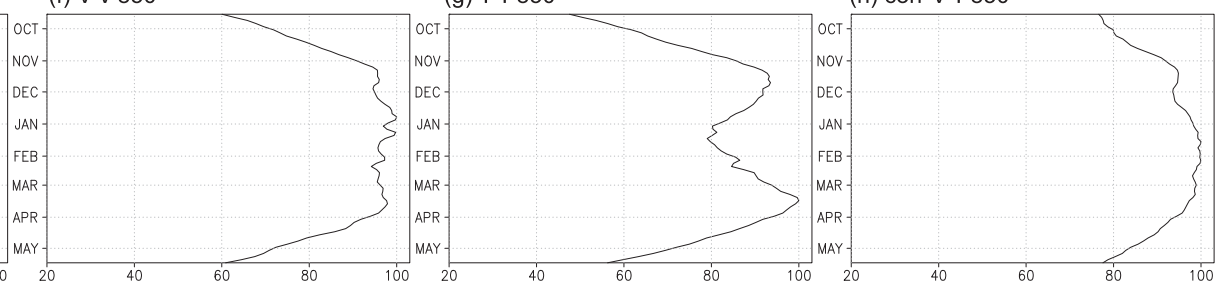

FIG. 11. (a)-(d) As in Fig. 10c, but for (a) $V^{\prime} T_{850}^{\prime}$, (b) $V^{\prime} V_{850}^{\prime}$, (c) $T^{\prime} T_{850}^{\prime}$, and (d) the correlation coefficient between $V^{\prime}$ and $T^{\prime}$ at 850 $\mathrm{hPa}$ averaged zonally in $150^{\circ} \mathrm{E}-180^{\circ}$ for the period of $1958 / 59-1985 / 86$. (e)-(h) As in (a)-(d), respectively, but for the period of $1986 /$ 87-2016/17. 
(a) $1958 / 59-1985 / 86$

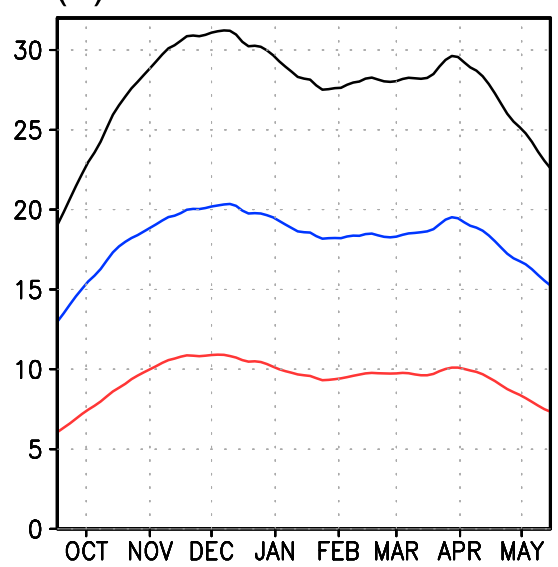

(c) $1958 / 59-1985 / 86$

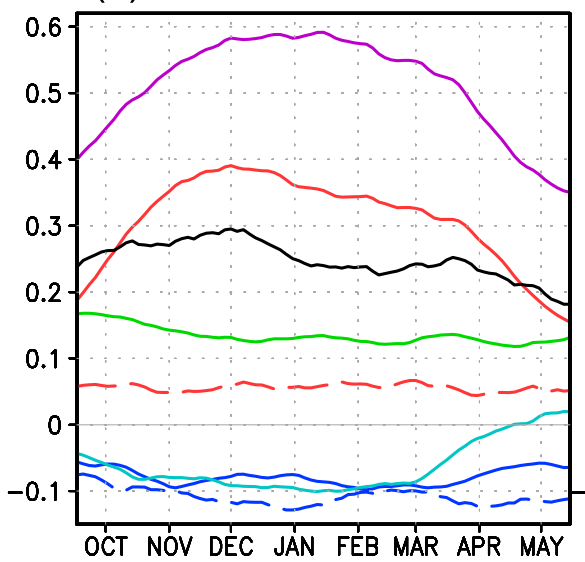

(b) $1986 / 87-2016 / 17$

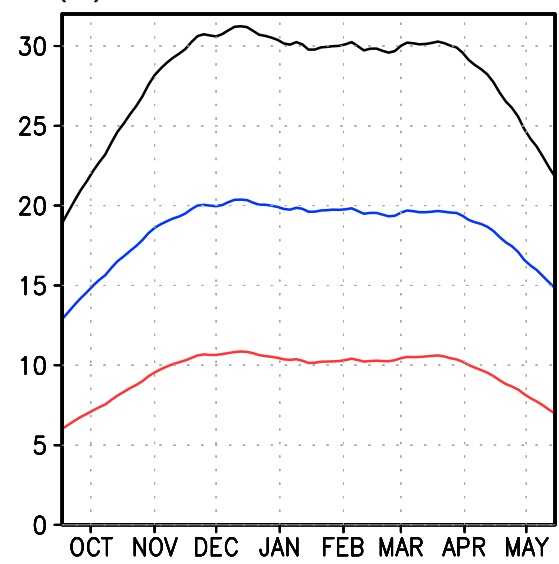

(d) $1986 / 87-2016 / 17$

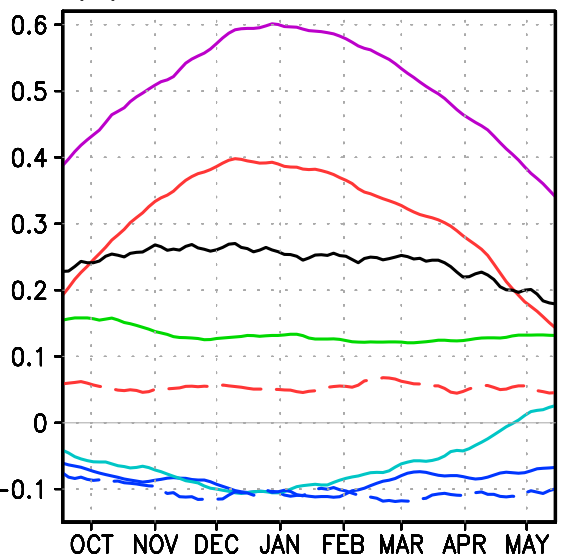

FIG. 12. (a),(b) As in Fig. 6a, but for the periods of 1958/59-1985/86 and 1986/87-2016/17, respectively. Units are $10^{18}$ J. (c),(d) As in Fig. 6c, but for the periods of 1958/59-1985/86 and 1986/87-2016/17, respectively. Units: day ${ }^{-1}$.

the midwinter Pacific storm-track activity is unlikely due to this barotropic effect. In fact, this interdecadal change in $\lambda_{\mathrm{CK}}$ cannot offset its counterpart in $\lambda_{\mathrm{CP}}$. The midwinter $\lambda_{\mathrm{EF}}$ (light blue lines in Figs. 12c,d) is negative and roughly comparable between the two periods. From late winter into spring, the seasonal weakening of the negative $\lambda_{\mathrm{EF}}$ is more gradual in the later period, contributing to the weaker spring recovery of eddy energy. A comparable contribution is made by $\lambda_{\mathrm{CK}}$ in early spring (Fig. B1). The net energy conversion from low-frequency variabilities (dashed lines in Figs. 12c,d) is negative, and its contribution to the midwinter suppression of $\lambda_{\text {Tot }}$ is slightly enhanced in the earlier period. When all the processes are combined, $\lambda_{\text {Tot }}$ for the midwinter NP storm track is thus slightly higher in the later period than in the earlier period (black lines in Figs. 12c,d). We have confirmed that the long-term modulations discussed above are statistically significant (see appendix B). The results show that the long-term modulations of the MWM can be interpreted, at least in part, from the viewpoint of eddy energetics.

\section{Summary and discussion}

In this study, we have delineated the detailed seasonal evolution of climatological-mean Eulerian statistics and the energetics for sub-weekly transient eddies along the NP storm track. As its distinct characteristic, the MWM of eddy activity is prominent particularly in upper-tropospheric $V^{\prime} V^{\prime}$ and lower-tropospheric $V^{\prime} T^{\prime}$ and $T^{\prime} T^{\prime}$. The distinct midwinter reduction in the midtropospheric upward wave-activity flux is consistent with the vertical structure of the MWM in the upper-level eddy activity $V^{\prime} V^{\prime}$ and EKE.

To investigate the maintenance mechanisms for the MWM, we have comprehensively evaluated the energetics for subweekly transient eddies along the NP storm track. In recognition of the dependence of any conversion/generation terms to eddy amplitude, we have calculated their energy conversion/ generation rate $(\lambda)$ normalized by the eddy total energy (EKE + EAPE), which is independent of eddy amplitude. We have revealed that the net normalized energy conversion/ generation rate $\left(\lambda_{\text {Tot }}\right)$ is indeed suppressed in midwinter. The 
reduction in the normalized EAPE conversion is found to play a substantial role especially in the reduction from its early-winter peak, whereas that of the energy outflux from the NP is particularly important for the spring recovery, among other processes contributing to the formation of the MWM in $\lambda_{\text {Tot }}$. Our results suggest that interaction between transient eddies and climatological-mean background state, especially the westerly jet and associated baroclinic zone, is central to the MWM over the NP and multiple processes are responsible. The midwinter reduction of $\lambda_{\mathrm{CP}}$ indicates that baroclinic eddy growth is suppressed in the real atmosphere despite the midwinter maximum of EGR (Hadas and Kaspi 2021). It is consistent with Schemm and Rivière (2019), whose results are based on the further normalization by the magnitude of background baroclinicity and only for the baroclinic energy conversion. We have verified that our results are quite similar when the ERA-Interim reanalysis (Dee et al. 2011) is used for the period of 1979/80-2016/17 in place of the JRA-55 (not shown).

In addition, we have applied the framework of energetics to the long-term modulations of the MWM of the NP stormtrack activity. As noted by Nakamura et al. (2002), the transition from $1985 / 86$ to $1986 / 87$ was striking, after which the MWM signal has become much less distinct in both $V^{\prime} V_{300}^{\prime}$ and $V^{\prime} T_{850}^{\prime}$. In the later period, the midwinter minima of $V^{\prime} V_{850}^{\prime}$ and $T^{\prime} T_{850}^{\prime}$ became less distinct or even almost vanished with the strongest positive $V^{\prime}-T^{\prime}$ correlation in midwinter, all of which contribute to the weakening of the MWM of $V^{\prime} T_{850}^{\prime}$. Correspondingly, the MWM of eddy energy (EKE and EAPE) has become less prominent in the later period.

Considering the modulation of the total eddy energy, the present study has shown that the long-term modulation in the MWM of the NP storm-track activity is consistent with the corresponding modulation in $\lambda_{\text {Tot }}$ in which all the energy conversion/generation terms are combined. In the earlier period (1958/59-1985/86), when the MWM was more prominent, $\lambda_{\text {Tot }}$ for the NP storm track exhibited a distinct MWM. The higher midwinter $\lambda_{\mathrm{CP}}$ after the transition is consistent with the stronger positive $V^{\prime}-T^{\prime}$ correlation over the western NP observed in winters of weak midwinter suppression found by Nakamura et al. (2002). Deng and Mak (2006) suggested that the efficiency of the barotropic energy conversion (CK) was comparably important to the energy transfer (from EAPE to EKE) associated with vertical motion (ET) in the difference between winters of the stronger and weaker MWM. Unlike in the present study, however, they did not focus on the EAPE conversion from the background state (CP). In addition, the present study also reveals that the most effective (negative) CK in midwinter is mainly due to the eddy momentum flux acting on the enhanced jet diffluence in its exit but not due to the enhanced lateral shear of the jet as assumed in the "barotropic governor" mechanism.

To assess whether the more distinct MWM in $\lambda_{\text {Tot }}$ is primarily due to eddy Eulerian statistics or climatological-mean background state, Fig. 13 compares the energetics for migratory eddies along the NP storm track between two different combinations of the eddy statistics and the background state: one is based on the eddy statistics in the earlier period and the background state in the later period, and vice versa for the other. By definition, EKE is independent of the background state. The eddy contributions to EAPE in the earlier and later periods are similar to the actual EAPE in the respective periods (Fig. 12). The $\lambda_{\text {Tot }}$ shows its more distinct midwinter suppression if evaluated for the eddy component in the earlier period under the background state in the later period (Figs. 13b,d). This result is quite similar to our result of long-term modulations shown in Fig. 12. These results suggest that the long-term modulations in the midwinter suppression of $\lambda_{\text {Tot }}$ is contributed to predominantly by the modulated eddy Eulerian statistics, especially in the poleward eddy heat flux, rather than directly by interdecadal modulation in the background westerlies.

The present study is the first to demonstrate that the net normalized energy conversion/generation rate $\lambda_{\text {Tot }}$ for subweekly transients along the NP storm track is indeed reduced in midwinter, largely owing to the baroclinic energy conversion $(\mathrm{CP})$ via poleward eddy heat flux with weakened temperature fluctuations especially for the reduction from early winter, among other mechanisms that also contribute positively to the MWM, including the energy flux term (EF) for the spring recovery. We have verified that the framework of energetics is useful for investigating the mechanisms for the MWM of the NP storm-track activity. It gives us a perspective of the MWM that encompasses various mechanisms proposed by previous studies. The barotropic conversion CK is presumably related to the excessively strong westerly jet, especially its diffluence in its exit region. The contribution of diabatic heating CQ includes the effect of low-level clouds in the cold sector of each cyclone. The net energy input through the lateral boundaries EF includes the "seeding effect" of cyclones from upstream. Specifically, the increasing $\lambda_{\mathrm{EF}}$ from the energy influx through the western boundary from midwinter into spring may be related to the upstream "seeding effect" (Penny et al. 2010; Zhao and Liang 2019), though its increase from autumn into midwinter is not consistent. In addition, the minimum or suppression of $\lambda_{\mathrm{CP}}$ is compatible with the suppressed baroclinic growth through the trapping of upper-tropospheric eddies into the subtropical jet core (Nakamura and Sampe 2002) over the central NP. The $\lambda_{\mathrm{CP}}$ is also compatible with the decreased Lagrangian coupling between the upper and lower part of the baroclinic wave over the NP (Hadas and Kaspi 2021).

Though its contribution to $\lambda_{\text {Tot }}$ is rather small, the positive zonal component of CP in midwinter (Fig. 7a) does not seem consistent with Schemm and Rivière (2019). It may be attributable to the difference between their analysis method and ours; they focused mainly on the energy conversion efficiency over the western NP north of $\sim 40^{\circ} \mathrm{N}$, while the $\lambda_{\mathrm{CP}}$ is calculated for the entire troposphere and over the whole NP in this study. The sign of zonal eddy heat flux is opposite between the mid- to upper troposphere and lower troposphere (not 
(a) Energy

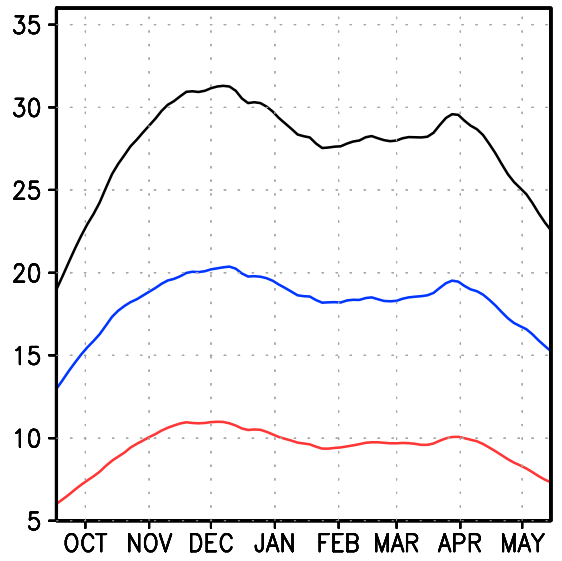

(c) Energy

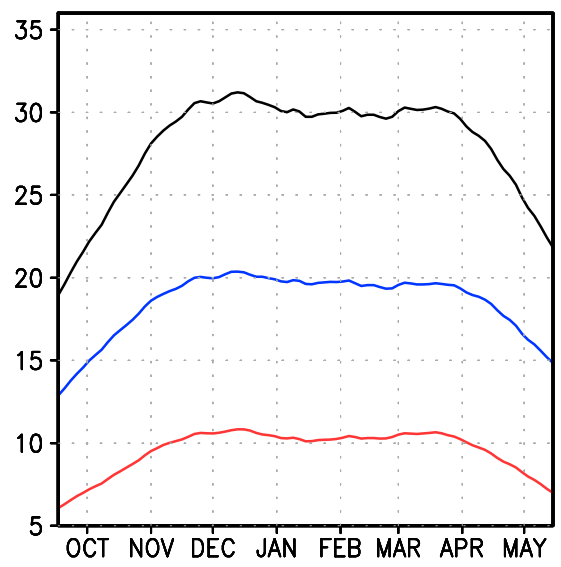

(b) Normalized rate

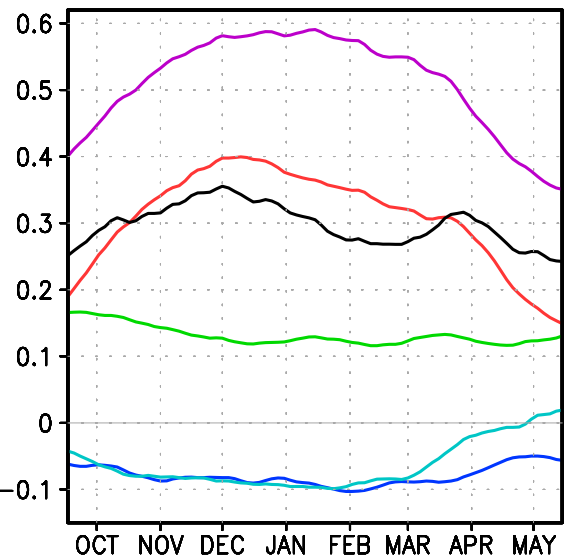

(d) Normalized rate

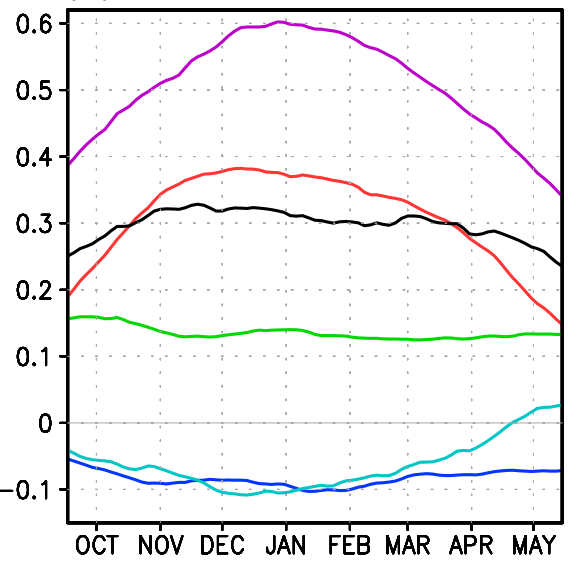

FIG. 13. (a) Climatological-mean seasonal evolution of EKE (blue), EAPE (red), and EKE + EAPE (black) integrated three-dimensionally over the NP $\left(10^{18} \mathrm{~J}\right)$, based on eddy statistics in 1958/59-1985/86 and the background state for 1986/87-2016/17. (b) As in (a), but for $\lambda_{\mathrm{CK}}$ (blue), $\lambda_{\mathrm{CP}}(\mathrm{red}), \lambda_{\mathrm{CQ}}$ (solid green), $\lambda_{\mathrm{CQ}}$ associated solely with precipitation (green dotted), $\lambda_{\mathrm{EF}}$ (light blue), and $\lambda_{\mathrm{EF}}$ (purple). Black line denotes $\lambda_{\mathrm{Tot}}$ relevant to the budget of EKE + EAPE associated with the background state (viz., $\mathrm{CK}+\mathrm{CP}+\mathrm{CQ}+\mathrm{EF}$ ). Units: day ${ }^{-1}$. (c), (d) As in (a) and (b), respectively, but based on the eddy statistics in 1986/87-2016/17 and the background state in 1958/59-1985/86.

shown), which ensures the advantage of the three-dimensional integration in the present study. Nonetheless, the discrepancy should be further investigated in future studies, as well as more detailed characteristics of the mechanisms for MWM. Particularly, the reduction in the upper-tropospheric $V^{\prime}-T^{\prime}$ correlation in midwinter and early spring, which probably contributes to the $\lambda_{\mathrm{CP}}$ reduction, will be addressed. Our results suggest that those processes previously discussed can be all operative in the formation of the MWM over the NP storm-track activity.

Recently, Schemm and Rivière (2019) and Schemm et al. (2021) have shown the usefulness of the Lagrangian perspective for studying MWM. The number of cyclones coming from the East China Sea (Schemm et al. 2021) may contribute also to the long-term modulation of MWM. Further investigation of the contribution from three-dimensional structure and characteristics of migratory cyclones to the MWM of the NP storm-track activity, focusing on Lagrangian perspective as in Schemm and Schneider (2018), will certainly be informative.

Acknowledgments. The authors are grateful to the three anonymous reviewers for their sound criticism and constructive comments on the earlier versions of this paper. This study is supported in part by the Japanese Ministry of Education, Culture, Sports, Science and Technology (MEXT) through the Arctic Challenge for Sustainability (ArCS-II), by the Japan Science and Technology Agency through COI-NEXT JPMJPF2013, by the Japanese Ministry of Environment through Environment Research and Technology Development Fund JPMEERF20192004, and by the Japan Society for the Promotion of Science (JSPS) through Grants-in-Aid for Scientific Research JP18H01278, JP19H05702 (on Innovative Areas 6102), and 20H01970. It is also supported by JSPS-ISF Joint Research Project (JPJSBP120218403). Y.K. acknowledges 
support from the JSPS Invitational Fellowship for Research in Japan that supported a sabbatical at the University of Tokyo and ignited this collaboration, for support from the Research Center for Advanced Technology and Science at the University of Tokyo and the Israeli Science Foundation (Grant 996/20).

Data availability statement. The JRA-55 atmospheric reanalysis is available online from the Japan Meteorological Agency at https://jra.kishou.go.jp/JRA-55/index_en.html as cited in Kobayashi et al. (2015) and Harada et al. (2016).

\section{APPENDIX A}

\section{Derivation of CKLF}

The derivation of CKLF is described. We start with the quasigeostrophic momentum equations in pressure coordinate:

$$
\begin{aligned}
& \frac{\partial u}{\partial t}=-u \frac{\partial u}{\partial x}-v \frac{\partial u}{\partial y}+f v-\frac{\partial \phi}{\partial x} \\
& \frac{\partial v}{\partial t}=-u \frac{\partial v}{\partial x}-v \frac{\partial v}{\partial y}-f u-\frac{\partial \phi}{\partial y}
\end{aligned}
$$

Then all the variables are decomposed into climatologicalmean, low-frequency, and high-frequency components. The equation for zonal momentum becomes

$$
\begin{aligned}
\frac{\partial}{\partial t}\left(u_{C}+u_{L}+u^{\prime}\right)= & -\left(u_{C}+u_{L}+u^{\prime}\right) \frac{\partial\left(u_{C}+u_{L}+u^{\prime}\right)}{\partial x} \\
& -\left(v_{C}+v_{L}+v^{\prime}\right) \frac{\partial\left(u_{C}+u_{L}+u^{\prime}\right)}{\partial y} \\
& +f\left(v_{C}+v_{L}+v^{\prime}\right)-\frac{\partial\left(\phi_{C}+\phi_{L}+\phi^{\prime}\right)}{\partial x},
\end{aligned}
$$

where primes denote high-pass-filtered fields, subscripts c signify the climatological-mean fields, and subscript $L$ lowpass-filtered anomalies, which has been calculated as a residual as $u_{L}=u-u_{C}-u^{\prime}$. The climatological variance of $u^{\prime}$ can be obtained by first multiplying (A3) with $u^{\prime}$ before taking the climatological average, while omitting cross-frequency terms that vanish as the climatological mean. Then, (A3) becomes

$$
\begin{aligned}
\frac{\partial}{\partial t}\left(\frac{1}{2} u^{\prime 2}\right)_{C}= & -\left[u^{\prime 2} \frac{\partial\left(u_{C}+u_{L}\right)}{\partial x}\right]_{C}-\left[u^{\prime} v^{\prime} \frac{\partial\left(u_{C}+u_{L}\right)}{\partial y}\right]_{C} \\
& -\left[\left(u_{C}+u_{L}\right) \frac{\partial}{\partial x}\left(\frac{1}{2} u^{\prime 2}\right)\right]_{C}-\left[\left(v_{C}+v_{L}\right) \frac{\partial}{\partial y}\left(\frac{1}{2} u^{\prime 2}\right)\right]_{C} \\
& -\left(u^{\prime} u_{L} \frac{\partial u_{L}}{\partial x}+u^{\prime} v_{L} \frac{\partial u_{L}}{\partial y}\right)_{C}+\left(f u^{\prime} v^{\prime}\right)_{C}-\left(u^{\prime} \frac{\partial \phi^{\prime}}{\partial x}\right)_{C}
\end{aligned}
$$

Similarly,

$$
\begin{aligned}
\frac{\partial}{\partial t}\left(\frac{1}{2} v^{\prime 2}\right)_{C}= & -\left[u^{\prime} v^{\prime} \frac{\partial\left(v_{C}+v_{L}\right)}{\partial x}\right]_{C}-\left[v^{\prime 2} \frac{\partial\left(v_{C}+v_{L}\right)}{\partial y}\right]_{C} \\
& -\left[\left(u_{C}+u_{L}\right) \frac{\partial}{\partial x}\left(\frac{1}{2} v^{\prime 2}\right)\right]_{C}-\left[\left(v_{C}+v_{L}\right) \frac{\partial}{\partial y}\left(\frac{1}{2} v^{\prime 2}\right)\right]_{C} \\
& -\left(v^{\prime} u_{L} \frac{\partial v_{L}}{\partial x}+v^{\prime} v_{L} \frac{\partial v_{L}}{\partial y}\right)_{C}-f\left(u^{\prime} v^{\prime}\right)_{C}-\left(v^{\prime} \frac{\partial \phi^{\prime}}{\partial y}\right)_{C}
\end{aligned}
$$

Combining (A4) and (A5) yields the equation for local tendency of EKE:

$$
\frac{\partial}{\partial t}(\mathrm{EKE})_{C}=\mathrm{CK}+\mathrm{CKLF}_{C}+\mathrm{ET}+(\text { advection of EKE })
$$

$$
\begin{aligned}
\mathrm{CKLF}= & {\left[\left(\frac{v^{2}-u^{\prime 2}}{2}\right)\left(\frac{\partial u_{L}}{\partial x}-\frac{\partial v_{L}}{\partial y}\right)-\left(u^{\prime} v^{\prime}\right)\left(\frac{\partial u_{L}}{\partial y}+\frac{\partial v_{L}}{\partial x}\right)\right] } \\
& -\left(u_{L} \frac{\partial \mathrm{EKE}}{\partial x}+v_{L} \frac{\partial \mathrm{EKE}}{\partial y}\right)-\left(u^{\prime} u_{L} \frac{\partial u_{L}}{\partial x}+u^{\prime} v_{L} \frac{\partial u_{L}}{\partial y}\right. \\
& \left.+v^{\prime} u_{L} \frac{\partial v_{L}}{\partial x}+v^{\prime} v_{L} \frac{\partial v_{L}}{\partial y}\right) .
\end{aligned}
$$

Note that we assume that the term $-(\partial / \partial p)\left(\phi^{\prime} \omega^{\prime}\right)_{C}$ becomes negligible after vertical integration. CKLF in (A7) corresponds to the cross-frequency term in Jiang et al. (2013), except that vertical momentum fluxes are neglected and the climatological mean is taken. The last term in (A7) is quite small as expected, and the sum of the first and second terms is found to be the same as $\mathrm{CK}_{\mathrm{LF}}$ (sign flipped) in Tanaka et al. [2016; their Eqs. (6) and (7)]. CPLF may be derived in a similar fashion with the thermodynamic equation.

\section{APPENDIX B}

\section{Statistical Significance of Long-Term Modulation}

Statistical significance of the modulation of normalized conversion/generation rates is assessed here. To evaluate statistical significance of differences in the rates between the earlier and later periods by $t$ test, standard deviations of the rates are calculated based on a random permutation of cold seasons by 20 times, the number of which is the same as that of the respective periods (i.e., 28 and 31), within the entire period (i.e., 59). Both climatological-mean eddy statistics and background states are calculated based on a given set of randomly selected cold seasons. Figure B1 shows that most of the distinct features in the differences of the normalized rates are statistically significant, including the midwinter reduction and early-winter/spring enhancement of $\lambda_{\text {Tot }}$. 


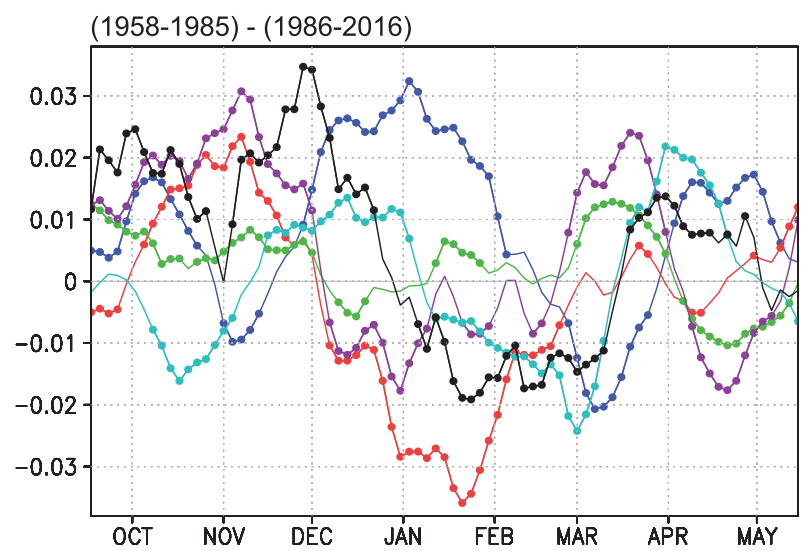

FIG. B1. Differences in climatological-mean $\lambda_{\mathrm{CK}}$ (blue), $\lambda_{\mathrm{CP}}$ (red), $\lambda_{\mathrm{CO}}$ (green), $\lambda_{\mathrm{EF}}$ (light blue), $\lambda_{\mathrm{EF}}$ (purple), and $\lambda_{\mathrm{Tot}}$ (black) over the North Pacific between the earlier (1958-85) and the later (1986-2016) periods. Units: day ${ }^{-1}$. Closed circles indicate statistically significant differences at the $99 \%$ confidence level by Student's $t$ test.

\section{REFERENCES}

Afargan, H., and Y. Kaspi, 2017: A midwinter minimum in North Atlantic storm track intensity in years of a strong jet. Geophys. Res. Lett., 44, 12-511, https://doi.org/10.1002/ 2017 GL075136.

Blackmon, M. L., 1976: A climatological spectral study of the 500 $\mathrm{mb}$ geopotential height of the Northern Hemisphere. $J$. Atmos. Sci., 33, 1607-1623, https://doi.org/10.1175/15200469(1976)033<1607:ACSSOT>2.0.CO;2.

_ , J. M. Wallace, N. C. Lau, and S. L. Mullen, 1977: An observational study of the Northern Hemisphere wintertime circulation. J. Atmos. Sci., 34, 1040-1053, https://doi.org/10.1175/ 1520-0469(1977)034<1040:AOSOTN>2.0.CO;2.

Chang, E. K., 1993: Downstream development of baroclinic waves as inferred from regression analysis. J. Atmos. Sci., 50, 2038-2053, https://doi.org/10.1175/15200469(1993)050<2038:DDOBWA > 2.0.CO;2.

- 2001: GCM and observational diagnoses of the seasonal and interannual variations of the Pacific storm track during the cool season. J. Atmos. Sci., 58, 1784-1800, https://doi.org/10. 1175/1520-0469(2001)058<1784:GAODOT >2.0.CO;2.

— , and S. Song, 2006: The seasonal cycles in the distribution of precipitation around cyclones in the western North Pacific and Atlantic. J. Atmos. Sci., 63, 815-839, https://doi.org/10. 1175/JAS3661.1.

— with the strength of upstream wave seeding? J. Climate, 25, 5768-5776, https://doi.org/10.1175/JCLI-D-11-00555.1.

—, S. Lee, and K. L. Swanson, 2002: Storm track dynamics. J. Climate, 15, 2163-2183, https://doi.org/10.1175/15200442(2002)015<02163:STD > 2.0.CO;2.

Christoph, M., U. Ulbrich, and P. Speth, 1997: Midwinter suppression of Northern Hemisphere storm track activity in the real atmosphere and in GCM experiments. J. Atmos. Sci., 54, 1589-1599, https://doi.org/10.1175/1520-0469(1997)054<1589: MSONHS $>2.0 . \mathrm{CO} ; 2$.

Dee, D. P., and Coauthors, 2011: The ERA-Interim reanalysis: Configuration and performance of the data assimilation system. Quart. J. Roy. Meteor. Soc., 137, 553-597, https://doi. org/10.1002/qj.828.

Deng, Y., and M. Mak, 2005: An idealized model study relevant to the dynamics of the midwinter minimum of the Pacific storm track. J. Atmos. Sci., 62, 1209-1225, https://doi.org/10. 1175/JAS3400.1.

$\longrightarrow$, and - 2006: Nature of the differences in the intraseasonal variability of the Pacific and Atlantic storm tracks: A diagnostic study. J. Atmos. Sci., 63, 2602-2615, https://doi.org/ 10.1175/JAS3749.1.

Eady, E. T., 1949: Long waves and cyclone waves. Tellus, 1, 33 52, https://doi.org/10.3402/tellusa.v1i3.8507.

Hadas, O., and Y. Kaspi, 2021: Suppression of baroclinic eddies by strong jets. J. Atmos. Sci., 78, 2445-2457, https://doi.org/10. 1175/JAS-D-20-0289.1.

Harada, Y., and Coauthors, 2016: The JRA-55 Reanalysis: Representation of atmospheric circulation and climate variability. $J$. Meteor. Soc. Japan, 94, 269-302, https://doi.org/10.2151/jmsj. 2016-015.

Harnik, N., and E. K. Chang, 2004: The effects of variations in jet width on the growth of baroclinic waves: Implications for midwinter Pacific storm track variability. J. Atmos. Sci., 61, 23-40, https://doi.org/10.1175/1520-0469(2004)061<0023:TEOVIJ >2.0. $\mathrm{CO} ; 2$.

Hotta, D., and H. Nakamura, 2011: On the significance of the sensible heat supply from the ocean in the maintenance of the mean baroclinicity along storm tracks. J. Climate, 24, 33773401, https://doi.org/10.1175/2010JCLI3910.1.

James, I. N., 1987: Suppression of baroclinic instability in horizontally sheared flows. J. Atmos. Sci., 44, 3710-3720, https://doi. org/10.1175/1520-0469(1987)044<3710:SOBIIH>2.0.CO;2.

Jiang, T., Y. Deng, and W. Li, 2013: Local kinetic energy budget of high-frequency and intermediate-frequency eddies: Winter climatology and interannual variability. Climate Dyn., 41, 961-976, https://doi.org/10.1007/s00382-013-1684-1.

Klinker, E., and P. D. Sardeshmukh, 1992: The diagnosis of mechanical dissipation in the atmosphere from large-scale balance requirements. J. Atmos. Sci., 49, 608-627, https://doi. org/10.1175/1520-0469(1992)049<0608:TDOMDI>2.0.CO;2.

Kobayashi, S., and Coauthors, 2015: The JRA-55 Reanalysis: General specifications and basic characteristics. J. Meteor. Soc. Japan, 93, 5-48, https://doi.org/10.2151/jmsj.2015-001.

Kosaka, Y., and H. Nakamura, 2010: Mechanisms of meridional teleconnection observed between a summer monsoon system and a subtropical anticyclone. Part I: The Pacific-Japan pattern. $J$. Climate, 23, 5085-5108, https://doi.org/10.1175/2010JCLI3413.1.

Lachmy, O., and N. Harnik, 2014: The transition to a subtropical jet regime and its maintenance. J. Atmos. Sci., 71, 1389-1409, https://doi.org/10.1175/JAS-D-13-0125.1.

- , and - 2016: Wave and jet maintenance in different flow regimes. J. Atmos. Sci., 73, 2465-2484, https://doi.org/10.1175/ JAS-D-15-0321.1.

Lau, N. C., and M. J. Nath, 1991: Variability of the baroclinic and barotropic transient eddy forcing associated with monthly changes in the midlatitude storm tracks. J. Atmos. Sci., 48, 2589-2613, https://doi.org/10.1175/1520-0469(1991)048<2589: VOTBAB $>2.0 . C O ; 2$.

Lee, S., and H. K. Kim, 2003: The dynamical relationship between subtropical and eddy-driven jets. J. Atmos. Sci., 60, 1490-1503, https://doi.org/10.1175/1520-0469(2003)060<1490:TDRBSA $>2$. $0 . \mathrm{CO} ; 2$.

Lee, S. S., J. Y. Lee, K. J. Ha, B. Wang, A. Kitoh, Y. Kajikawa, and M. Abe, 2013: Role of the Tibetan Plateau on the annual 
variation of mean atmospheric circulation and storm-track activity. J. Climate, 26, 5270-5286, https://doi.org/10.1175/ JCLI-D-12-00213.1.

Madonna, E., C. Li, and J. J. Wettstein, 2019: Suppressed eddy driving during southward excursions of the North Atlantic jet on synoptic to seasonal time scales. Atmos. Sci. Lett., 20, e937, https://doi.org/10.1002/asl.937.

Martineau, P., H. Nakamura, Y. Kosaka, and A. Yamamoto, 2020: Importance of a vertically tilting structure for energizing the North Atlantic Oscillation. Sci. Rep., 10, 12671, https://doi.org/10.1038/s41598-020-69551-5.

Nakamura, H., 1992: Midwinter suppression of baroclinic wave activity in the Pacific. J. Atmos. Sci., 49, 1629-1642, https://doi. org/10.1175/1520-0469(1992)049<1629:MSOBWA > 2.0.CO;2.

— , and T. Sampe, 2002: Trapping of synoptic-scale disturbances into the North-Pacific subtropical jet core in midwinter. Geophys. Res. Lett., 29, 2002, https://doi.org/10.1029/2002GL015535.

—, M. Tanaka, and J. M. Wallace, 1987: Horizontal structure and energetics of Northern Hemisphere wintertime teleconnection patterns. J. Atmos. Sci., 44, 3377-3391, https://doi.org/ 10.1175/1520-0469(1987)044<3377:HSAEON>2.0.CO;2.

- T. Tzumi, and T. Sampe, 2002: Interannual and decadal modulations recently observed in the Pacific storm track activity and East Asian winter monsoon. J. Climate, 15, 1855-1874, https://doi.org/10.1175/1520-0442(2002)015<1855:IADMRO >2. $0 . \mathrm{CO} ; 2$.

—, T. Sampe, Y. Tanimoto, and A. Shimpo, 2004: Observed associations among storm tracks, jet streams, and midlatitude oceanic fronts. Earth Climate: The Ocean-Atmosphere Interaction, Geophys. Monogr., Vol. 147, Amer. Geophys. Union, 329-345.

Novak, L., T. Schneider, and F. Ait-Chaalal, 2020: Midwinter suppression of storm tracks in an idealized zonally symmetric setting. J. Atmos. Sci., 77, 297-313, https://doi.org/10.1175/ JAS-D-18-0353.1.

Park, H. S., J. C. Chiang, and S. W. Son, 2010: The role of the central Asian mountains on the midwinter suppression of North Pacific storminess. J. Atmos. Sci., 67, 3706-3720, https://doi.org/10.1175/2010JAS3349.1.

Penny, S., G. H. Roe, and D. S. Battisti, 2010: The source of the midwinter suppression in storminess over the North Pacific. $J$. Climate, 23, 634-648, https://doi.org/10.1175/2009JCLI2904.1.

— D. S. Battisti, and G. H. Roe, 2013: Examining mechanisms of variability within the Pacific storm track: Upstream seeding and jet-core strength. J. Climate, 26, 5242-5259, https:// doi.org/10.1175/JCLI-D-12-00017.1.

Rivière, G., and A. Joly, 2006: Role of the low-frequency deformation field on the explosive growth of extratropical cyclones at the jet exit. Part I: Barotropic critical region. J. Atmos. Sci., 63, 1965-1981, https://doi.org/10.1175/JAS3728.1.

— S. Berthou, G. Lapeyre, and M. Kageyama, 2018: On the reduced North Atlantic storminess during the last glacial period: The role of topography in shaping synoptic eddies. $J$. Climate, 31, 1637-1652, https://doi.org/10.1175/JCLI-D-170247.1.

Robert, L., G. Rivière, and F. Codron, 2017: Positive and negative eddy feedbacks acting on midlatitude jet variability in a three-level quasigeostrophic model. J. Atmos. Sci., 74, 16351649, https://doi.org/10.1175/JAS-D-16-0217.1.

Schemm, S., and T. Schneider, 2018: Eddy lifetime, number, and diffusivity and the suppression of eddy kinetic energy in midwinter. J. Climate, 31, 5649-5665, https://doi.org/10.1175/ JCLI-D-17-0644.1.

- , and G. Rivière, 2019: On the efficiency of baroclinic eddy growth and how it reduces the North Pacific storm-track intensity in midwinter. J. Climate, 32, 8373-8398, https://doi. org/10.1175/JCLI-D-19-0115.1.

- , H. Wernli, and H. Binder, 2021: The storm-track suppression over the western North Pacific from a cyclone life-cycle perspective. Wea. Climate Dyn., 2, 55-69, https://doi.org/10. 5194/wcd-2-55-2021.

Stephenson, D. B., 1995: The impact of changing the horizontal diffusion scheme on the northern winter climatology of a general circulation model. Quart. J. Roy. Meteor. Soc., 121, 211-226, https://doi.org/10.1002/qj.49712152110.

Sung, M. K., H. Y. Jang, B. M. Kim, S. W. Yeh, Y. S. Choi, and C. Yoo, 2019: Tropical influence on the North Pacific Oscillation drives winter extremes in North America. Nat. Climate Change, 9, 413-418, https://doi.org/10.1038/s41558-019-0461-5.

Takaya, K., and H. Nakamura, 2001: A formulation of a phase-independent wave-activity flux for stationary and migratory quasigeostrophic eddies on a zonally varying basic flow. J. Atmos. Sci., 58, 608-627, https://doi.org/10.1175/1520-0469(2001)058<0608: AFOAPI $>2.0 . \mathrm{CO} ; 2$.

Tanaka, S., K. Nishii, and H. Nakamura, 2016: Vertical structure and energetics of the western Pacific teleconnection pattern. J. Climate, 29, 6597-6616, https://doi.org/10.1175/JCLI-D-150549.1.

Trenberth, K. E., 1986: An assessment of the impact of transient eddies on the zonal flow during a blocking episode using localized Eliassen-Palm flux diagnostics. J. Atmos. Sci., 43, 2070-2087, https://doi.org/10.1175/1520-0469(1986)043<2070: AAOTIO $>2.0 . \mathrm{CO} ; 2$.

Whitaker, J. S., and P. D. Sardeshmukh, 1998: A linear theory of extratropical synoptic eddy statistics. J. Atmos. Sci., 55, 237-258, https://doi.org/10.1175/1520-0469(1998)055<0237:ALTOES >2.0. $\mathrm{CO} ; 2$.

Yuval, J., and Y. Kaspi, 2018: Eddy sensitivity to jet characteristics. J. Atmos. Sci., 75, 1371-1383, https://doi.org/10.1175/JASD-17-0139.1.

- , H. Afargan, and Y. Kaspi, 2018: The relation between the seasonal changes in jet characteristics and the Pacific midwinter minimum in eddy activity. Geophys. Res. Lett., 45, 999510002, https://doi.org/10.1029/2018GL078678.

Zhang, Y., and I. M. Held, 1999: A linear stochastic model of a GCM's midlatitude storm tracks. J. Atmos. Sci., 56, 3416-3435, https://doi.org/10.1175/1520-0469(1999)056<3416:ALSMOA >2. $0 . \mathrm{CO} ; 2$.

Zhao, Y., and X. S. Liang, 2019: Causes and underlying dynamic processes of the mid-winter suppression in the North Pacific storm track. Sci. China Earth Sci., 62, 872-890, https://doi.org/ 10.1007/s11430-018-9310-5. 